\title{
Agustina Serrano Pérez
}

Facultad de Teología

Pontificia Universidad Católica de Chile

\section{Contentarse con la finitud o atreverse a gustar la transcendencia (*)}

\author{
Aproximación al dilema de la razón en Santa Teresa de Ávila
}

\section{INTRODUCCIÓN}

Santa Teresa de Ávila es redescubierta en la segunda mitad del XX y se le adjudica un magisterio empírico de la experiencia. A partir de la separación entre mística y teología, entre experiencia de fe y ciencia de la fe, se convoca hoy, de nuevo, a un diálogo que supere el dilema entre finitud e infinitud. La autora sigue vigente, presente en la postmodernidad; sus obras se venden en los quioscos, junto a libros, revistas y videos de los más variados y coyunturales temas (1).

En el siglo XXI, como algunos pensadores han indicado, el cristiano será una persona que ha experimentado algo, porque la experiencia es indispensable si se concibe la fe como el encuentro de todo el hombre con Dios. Esa vivencia de fe sentida, entendida y comunicada fue el gran mérito que la autora aunó y transmitió a las futuras generaciones. Para el hombre y la cultura de nuestro tiempo, su testimonio aporta pistas que enfocan adecuadamente el dilema de la razón humana a diversos niveles (2).

La pregunta por el después hace emerger el gran dilema de la razón: encorvarse sobre sí misma, o abrirse desde sí a la transcendencia. Nuestra autora es una interpelación permanente porque llega a las raíces de la condición humana, toca el centro neurálgico del ser humano de siempre: el lugar de la presencia de Dios. Y todo esto lo ha escrito de un modo razonable (verdadero), significativo (bueno) y atractivo (bello) (3).

(*) Este estudio responde al Proyecto FONDECYT Regular 2004, N 1040763, titulado "El dilema de la razón humana en Hildegard von Bingen, Ricardo de San Víctor y Teresa de Ávila", cuyo investigador responsable es Anneliese Meis y los coinvestigadores son Juan Francisco Pinilla, Carlos Casale y Agustina Serrano.

(1) Cf. Álvarez, T., "El futuro de nuestro pasado. Teresa de Jesús y la seducción de los místicos", Monte Carmelo 109 (2001) 35-46.

(2) Cf. Ros, S., "Mística y siglo XXI: La seducción de los místicos Teresa de Jesús y Juan de la Cruz", Monte Carmelo 109 (2001) 47-67.

(3) Cf. Ros, S., "Experiencia y transmisión de la fe con Teresa de Jesús", Revista de Espiritualidad 61 (2002) 231-254. 
La obra Castillo Interior aborda el crecimiento humano, en las cuatro primeras moradas se alcanza hasta la llamada "primera mitad de la vida". Haciendo un paralelismo con la edad cronológica se sitúa entre los dieciséis años, momento de plantearse las opciones fundamentales de la existencia, hasta los cuarenta años, aproximadamente, edad en la que se produce un quiebre fundamental. El proceso, desde la primera morada, se inicia con una invitación a la conversión. Las segundas moradas se presentan como un tiempo de lucha para la opción radical. Aparecen las ambigüedades y las sequedades en las terceras. Y en las cuartas moradas, se explica el significado del contento y el gusto (4).

La hipótesis que se presenta en esta investigación es: la razón humana puede resolver su dilema congénito. En la obra estudiada se formula de esta manera: contentarse con la finitud o atreverse a gustar la transcendencia. Y se apuesta porque el Espíritu Santo capacita a la razón para superar el dilema y plenificarse asombrosamente en el amor.

A partir del Vaticano II se concede valor a los místicos en la transmisión de la fe y en el enriquecimiento de la tradición eclesial. Varios teólogos reconocen la "misión teológica" de la obra de Teresa como crítica a la teología (5). Es necesaria una apertura al contacto íntimo con el Misterio, esa relación acontece con alguna experiencia (6) intra-mundana, como Presencia amorosa que sustenta al ser humano (7). La autora propone la acogida de lo transcendente cimentándose en Dios (8), porque descubre que lo más profundo de ella es un diamante que encierra todo en sí (9). La vivencia religiosa no será de masas sino de élites y se replegará en lo esencial: la existencia de Dios y "de rebote el de la existencia y supervivencia del hombre" (10). El dilema humano se afronta penetrando al

(4) Cf. Álvarez, T., Guía al interior del Castillo. Lectura espiritual de las “Moradas, Burgos, Editorial Monte Carmelo, 2000, 314 pp. También, "Introducción a El Castillo interior", en Teresa de Jesús. Doctora de la Iglesia. Obras Completas, 5. ed., Burgos, Editorial Monte Carmelo, 1987, 765-786.

(5) Cf. Rahner, K., Schillebeeckx, E., y otros, en Revista de Espiritualidad 29 (1970) 299-328. También Cf. Ros, S., "Mística y siglo XXI...", 47-67. Esa nueva sensibilidad de los primeros años del postconcilio favoreció la comprensión doctrinal de Teresa, pues estaba muy en consonancia con las preocupaciones de la teología contemporánea. En este siglo de cambios rápidos, de crisis de fe en Dios, de agotamiento de un modelo racional-positivista como único medio de conocimiento, se necesita una racionalidad que asuma todas las cualidades antropológicas y de ese modo capta y vive la realidad en toda su plenitud, incluso con la pretensión de creatividad en las formas históricas de ser cristiano.

(6) Cf. Baltasar, H.U. von, Gloria. Una estética teológica, vol. I, Madrid, Editorial Encuentro, $1985,201$.

(7) Cf. Zubiri, X., El hombre y Dios, 6. ed., Madrid, Alianza Editorial, 1998, 326.

(8) En la apertura a lo infinito se da una fuerte impresión de realidad (noética) y una transformación de la vida (ética). Teresa une ambas señales en esta idea, la experiencia de Dios deja luz en el entendimiento y firmeza en la verdad (V 15, 10; $5 \mathrm{M} \mathrm{1,9).}$

(9) Cf. Ros, S., "Experiencia y transmisión...", 254. El autor, refiriéndose a nuestra autora, cita unas palabras de Pedro Cerezo, "alumbró una nueva forma de ser, supuso el nacimiento de la intimidad moderna, abierta en éxtasis de transcendencia desde su más profundo centro, medio siglo antes de que el giro cartesiano viniera a cerrarla sobre sí misma en la autarquía de un solipsismo intrascendible. En una época, por lo demás egoísta y secularizadora, /.../, Teresa de Ávila /... / Era el quiebro más elegante, la ironía más fina que se podía imaginar contra el mero humanismo".

(10) Cf. Álvarez, T., "El futuro de nuestro pasado...", 45. 
interior del castillo, que es un símbolo del misterio del ser humano en su relación con el mundo y con Dios (11).

Se ofrecen valiosos aportes que dan acceso a lo profundo de la vida humana recorriendo las distintas moradas, a través de las cuales se afrontan los diversos dilemas existenciales (12). El ser humano es disperso y a la vez posee una capacidad que lo lleva más allá de sí posibilitando la apertura a lo divino (13).

Para terminar, se ofrecen, sintéticamente, algunos de los dilemas que se plantean a lo largo de la obra. Desde una perspectiva literaria, el dilema se plantea entre la orden de escribir y la voluntad de escritora. Así el deseo teresiano de ser leída frente al no atreverse; la necesidad de romper sus cadenas para comunicarse y la pretensión de no levantar sospechas $(6 \mathrm{M} 6,3)$ Su declaración de que escribe torpe y su gusto por la obra realizada (Epílogo, 1) Su palabra no es mera espontaneidad, controla sus modos expresivos para no causar recelos y para llegar al destinatario. Desde el punto de vista doctrinal, un dilema es que sin ser letrada se sitúa como instancia crítica de la teología (V 40,8). Cobra especial relevancia la lucha entre lo efímero y lo seguro; lo terreno y lo eterno; lo pasajero de esta vida y lo permanente de la eterna. Vive con urgencia el acierto en las decisiones fundamentales ante la brevedad de la vida (14).

\section{EL DILEMA PUEDE SER FECUNDO: LIBERTAD Y CREATIVIDAD}

El dilema puede ser fecundo cuando la razón asume la disyuntiva humana, gracias a la libertad. El dilema puede ser fecundo, gracias a la creatividad, cuando el amor ensancha las relaciones interpersonales en lo cotidiano. Es decir, el dilema es fecundo cuando la razón se alía con la libertad y el amor con la creatividad.

\section{La razón afronta el dilema desde la libertad}

El dilema fundamental, encorvarse sobre sí mismo o abrirse a la transcendencia, puede ser significativo y eficaz si la razón humana asume la disyuntiva anterior sin estancarse en ella. Es decir, avanza hacia delante y sigue creciendo.

(11) Cf. Álvarez, T., Guía al interior... Teresa expone con profundidad la dignidad del ser humano llamado a la comunión. Cada persona es un castillo y Teresa invita a entrar y conocerse. Se advierte que la vida en el castillo no es fácil: hay combate, ambigüedad, sequedad, aridez. A la altura de las cuartas moradas se hace más palpable el dilema, se alcanza una cima en que se otea el paisaje y se invita al paso a la otra vertiente. No se promete ningún idilio sino una afanosa y penosa, aunque gustosa, búsqueda que no escatima ningún esfuerzo, pero que entrevé con optimismo un desenlace afortunado.

(12) Cf. Herraiz, M., Introducción al Castillo Interior de Teresa de Jesús, Burgos, Editorial Monte Carmelo, 2001, 140 pp.

(13) Cf. Castellano, J., "Lectura de un símbolo teresiano", Revista de Espiritualidad 41 (1982) 531566. También "Conocimiento y experiencia de Dios Amor en los místicos cristianos", en Dios Amor en la tradición cristiana y en los interrogantes del hombre contemporáneo, Madrid, Editorial Ciudad Nueva, 1993, 136-183.

(14) Cf. Ros, S., "Los estudios teresianos: panorama de actualidad y perspectivas de tratamiento", Teresianum 38/2 (1987) 149-209. especialmente 192 y 198-199. 
En el texto de Teresa se descubre que la razón afronta el dilema desde la libertad respecto a todo lo creado, en la relación con los semejantes y la libertad referida a la transcendencia.

\subsection{Libertad respecto a todo lo creado}

La libertad discierne, permanentemente, el mejor camino para el conocimiento; acepta el proyecto de Dios desde el anonadamiento; transforma las ocasiones de tentación en posibilidades de conversión; y vive con esperanza la realidad humana.

La otra mirada afirma que la razón discierne el mal y pretende la voluntad de Dios; y puede aceptar que la prueba purifica y que la paciencia es buena y necesaria consejera.

\section{a) Discernimiento y pretensión}

La libertad se desarrolla en referencia a todo lo creado porque es una realidad situada. Por ello se mueve entre el discernimiento y la pretensión: discierne el poder del mal $(2 \mathrm{M} 1,5)$ y pretende la voluntad de Dios, que consiste en conformarse a Cristo en su kenosis $(2 \mathrm{M} 1,8)$.

El discernimiento del mal con sus consecuencias, y la opción razonada por la lucha es signo y expresión de la libertad humana. Se señala la enorme dificultad del proceso de profundización y conocimiento (15).

La autora describe el poder del mal a través de la imagen de la mordedura de víbora. Así como el veneno hincha y mata, así sucede si se vive en la superficialidad y en lo evidente (16). La debilidad de la fe es tal, que ni estimula ni mueve, sino que es inerte frente a una realidad que arrastra. De ese modo, a pesar de conocer las consecuencias, se desea y persigue lo aparente, aunque esté al margen de la propuesta de mayor humanización (17). Pero también, la costumbre se vence por razones, y la gracia de Dios ayuda frente al mal.

El dilema se puede plantear del siguiente modo: sometimiento al poder del mal o alianza con la debilidad humana. La disyuntiva se aborda desde la acción conjunta de hombre y Dios. Así, el ser humano, desde su limitación, decide libremente la sanación costosa y exigente, y la gracia de Dios ayuda a no perecer en la muerte. Especialmente, ciertas personas capacitadas, en esta situación, sufren mucho porque aparecen mayores obstáculos que impiden el seguimiento, el conocimiento de sí, y la llegada a la meta (18).

La lucha interior, buscando el sentido de la existencia, consiste en no conformarse con la costumbre, vida encorvada sobre sí misma, sino atreverse a la apertura a la gracia. La relación del hombre con Dios se ve interferida por la incredulidad y la muerte que se evidencian a través de ciertas polaridades: mal-bien; fe-increduli-

(15) Cf. 2M 1, 5.

(16) Ib., "la costumbre en las cosas de vanidad y el ver que todo el mundo trata de esto".

(17) Ib., "está tan muerta la fe que queremos más lo que vemos que lo que ella nos dice".

(18) Ib., "en especial si entiende el demonio que tiene aparejo en su condición y costumbres para ir muy adelante". 
dad, sanar-morir; paraíso-infierno; la gracia de Dios o el poder del demonio. Todo ello se sintetiza en el dilema humano de entrar dentro o salir fuera. Es decir, la propuesta es el avance por las sucesivas moradas hasta el centro donde se halla Dios, o el abandono hasta salir fuera por las dificultades. Quien vive conforme al mundo se acomoda a lo que sucede en el exterior: la destrucción de la vida; lo nocivo a la salud espiritual; lo perjudicial a las buenas costumbres, etc. (19). Pero también, desde el comienzo del texto se hace la adecuada propuesta: es posible el camino hacia el centro de sí mismo; hay "razones... para vencer..." (20).

En definitiva, la razón descubre el poder destructivo del mal y la debilidad de la fe empequeñecida ante la fuerza de lo cotidiano. Pero se entrevé y vislumbra la acción de Dios junto al empeño humano, libre y esforzado, ayuda el avance en el conocimiento y evita que el dilema arruine.

El descubrimiento de la voluntad de Dios es una gracia regalada al ser humano; Dios conoce y ama al hombre y sabe sus necesidades verdaderas. Dios siempre, a su manera y libremente, acompaña, impulsa y recompensa el esfuerzo humano. En esto consiste la sabiduría divina a la cual el hombre no accede fácilmente (21).

A pesar de la ignorancia humana que exige a Dios, desconociendo el sentido final de la existencia, es posible el camino de la plenitud al conformarse la voluntad humana con la divina. La persona atrevida es capaz del empeño en el proceso de autoconocimiento y esa disposición ofrece garantías para la construcción de un edificio firme y sólido (22). El dilema, entre la dificultad del proceso o el abandono, se resuelve pretendiendo avanzar en la interiorización para llegar a la perfección. La tentación se presenta, en ocasiones, como miedo ante la propuesta divina, por eso el hombre no acepta la kenosis, y prefiere el desconocimiento del plan salvífico de Dios. Sin embargo, la ignorancia divina, más sabia que la sabiduría humana (1Cor 1, 25), revela que todo el bien consiste en adecuarse a la voluntad de Dios bebiendo el cáliz (Mt 20,22). El bien de la creación pasa por el dolor de la salvación; el bien del hombre consiste en el pacto con la propia debilidad, que aunque parece lo más alejado de Dios, es requerida por la realización de la posibilidad humana (23). La tentación, como sequedad y malos pensamientos, fortalece si no se sucumbe a ella (24). El dilema se plantea entre el empeño humano desde la debilidad, o la dejadez desde la soberbia. Según la primera opción el ser humano camina en el proceso y avanza conformándose a la voluntad de Dios.

La razón libremente se configura a la voluntad de Dios, a su proyecto, contando con las dificultades y confiando que es el camino hacia la humanización. La mayor tentación es la negación de la voluntad de Dios. El dilema del abandono ante la dificultad se afronta con libertad apostando por el progreso en la interiorización.

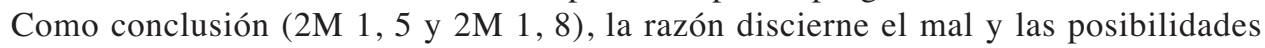
humanas y apuesta por configurarse a la voluntad de Dios.

(19) Ib., "van tras estas cosas visibles... estas cosas emponzoñosas".

(20) Cf. $2 \mathrm{M} 1,5$.

(21) Cf. $2 \mathrm{M} 1,8$.

(22) Ib., "trabajar y determinarse y disponerse con cuantas diligencias".

(23) Ib., "hacer lo que es en nosotros". 
b) Prueba y paciencia

La libertad situada, al enfrentarse a la prueba, capacita para el reconocimiento de la tentación $(3 \mathrm{M} 2,1)$, y para la paciencia con la condición humana $(4 \mathrm{M} 1,14)$. El dilema es fecundo cuando la razón, aliada a la libertad, se sitúa, ante todo lo creado, con paciencia y en clave de purificación.

La razón reconoce la tentación y admite la prueba como medida necesaria para el crecimiento en la humildad, el desasimiento y el avance hacia la plena conversión (25).

Este texto se refiere a personas que viven en equilibrio personal y controlando la realidad, creyendo que ya todo está conseguido (26). Aunque se lleva tiempo viviendo con un programa de vida estable, la razón reconoce la posibilidad de ser tentado e incluso de sucumbir en la prueba. En esta situación existencial aunque la vida en paz se trastoca en angustia, resulta que la prueba es ocasión de mayor profundidad (27). El dilema humano se centra en la disyuntiva de vida en armonía o en desasosiego. Se tiende a optar por uno de los polos, pero, también, cabe la posibilidad de que la prueba, aunque rompe una inicial estabilidad, provoca el crecimiento encaminando a la cima del proceso. Es el examen práctico de la humildad ejercitado a través del despojo, hasta la conversión definitiva. ¿Por qué la prueba es necesaria para la purificación? El pecado alteró el orden creatural y Dios lo salva por la debilidad y el dolor; asumiendo lo más frágil realiza la salvación por el Espíritu (Rm 5, 3-5).

La razón crece en libertad y el dilema fructifica aceptando la condición humana con paciencia (28).

Toda persona se encuentra inserta en un determinado contexto histórico y en una determinada situación existencial (29). La razón se esfuerza en comprender lo que sucede, y desde la formación busca el sentido a la existencia, incluyendo la tolerancia con la limitación, y la apertura a Dios (30). La paciencia estimula el entendimiento y el discernimiento (31). El esfuerzo cobra sentido al comprender la acción de Dios en toda la vida humana; y cuando se descubre el amor como el fundamento y el sentido de la existencia (32). Hay estorbos que provocan beneficios y esto acontece en el

(24) Ib., "Procuremos... guardarnos de estas sabandijas ponzoñosas; ... que nos persigan... nos aflijan... nos muerdan".

(25) Cf. 3M 2, 1

(26) Ib., "han llegado a este estado y estado y vivido muchos años en esta rectitud y concierto de alma y cuerpo... señores del mundo".

(27) Ib., "muchos años, ... rectitud y concierto... inquietud y apretamiento de corazón ... darles consejo no hay remedio".

(28) Cf. 4M 1, 14.

(29) En el tiempo que escribe esta cuarta morada se entera de la muerte de Nicolás Ormaneto, nuncio papal que defendía la reforma teresiana, este acontecimiento fue un gran drama en la vida de Teresa, Cf. Álvarez, T., Guía... 75.

(30) Ib., "Hay más y menos en este estorbo conforme a la salud y a los tiempos... padezca la pobre alma... y nos entendamos y lo que hace la flaca imaginación y el natural y demonio no pongamos la culpa al alma, ... Y porque no basta lo que leemos y nos aconsejan, que es que no hagamos caso de estos pensamientos... hasta que el Señor nos quiera dar luz".

(31) Ib.: "para las que poco sabemos no me parece tiempo perdido todo lo que gasto en declararlo más ... lo que hace la flaca imaginación y el natural y demonio".

(32) Ib.: "padezca... aprovechará... el Señor... (da) luz... salud... tiempos". 
momento oportuno: cuando hay capacidad humana madura para el conocimiento y el amor. La misma realidad humana global, se va reinterpretando; la limitación se hace aliada y se relativiza lo accesorio, accediendo a vivir en la profundidad de lo fundamental. Se llega a este nivel en la cima de la ascética (4M) y el Señor concede su gracia. Se necesita una preparación progresiva para no deslumbrarse por la luz que Dios da; únicamente, cuando el hombre puede asumir, entonces Dios otorga.

Ante el dilema culpa o padecimiento, es posible posicionarse a favor de la paciencia con medios adecuados, al estilo de Jesús que padece sin culpa, como Jesús. El fruto que nace despeja el gran dilema existencial y consiste en la sabiduría por la que se comprende la realidad y toda la existencia desde una visión integral. La razón admite la tentación y la prueba purificadora, y apuesta por la paciencia hacia la condición humana, que a su debido momento conocerá y alcanzará la visión total.

En definitiva, la razón afronta el dilema desde la libertad respecto a lo creado discerniendo el mal y las posibilidades humanas, por ello admite la tentación y la prueba purificadora. En el otro polo, la razón se atreve, arriesga y opta por el proyecto de Dios aceptando y asumiendo con paciencia la limitación humana.

\subsection{Libertad en relación con los semejantes}

La relación capacita para afrontar fecundamente el dilema existencial porque toda fecundidad requiere la colaboración de otros. En esa interdependencia, la razón reconoce la condición humana y la posibilidad de la plenitud (33). Los otros impulsan a lo definitivo a través del contraste, el estudio, y el conocimiento (34). La razón descubre la limitación y la capacidad de profundidad (35). El dilema es fecundo cuando la razón se alía con la libertad en relación con el prójimo.

En la relación con Dios se experimenta la ambigüedad, pero la razón asume la posibilidad de llegar a la santidad (36). El descubrimiento de la limitación común existencial posibilita la humildad y la obediencia, asimismo, la propia aceptación es la única postura válida y adecuada en la relación con los otros y con Dios. La pretensión humana aspira a lo máximo y Dios da su apoyo; el no fiarse ciegamente de sí posibilita confiar en la misericordia de Dios. El reconocimiento de que Dios habita lo humano conduce a la asunción de la limitación: en la debilidad se muestra la fuerza (2Cor 12, 1-10). El camino hasta la plenificación es obra del sujeto y de la misericordia de Dios (37). La confianza en Jesucristo capacita para mayores riesgos, porque el amor de Dios transforma a cada ser humano. El dilema entre la indigencia del hombre o la misericordia de Dios, se resuelve en la gracia, que habilita y transforma al hombre. La lucha por asumirse se logra confiando, sabiendo que el hombre es templo de Dios. En el fondo es confianza que siempre se cumple: ¡Dios es fiel a sus promesas!

(33) Cf. $3 \mathrm{M} 1,3$.

(34) Cf. $3 \mathrm{M} \mathrm{2,} 12$.

(35) Cf. 4M 1, 12.

(36) Cf. $3 \mathrm{M} 1,3$.

(37) Ib., "quisierais que hubiera sido muy santa... que no puedo dejar de ser la que he sido". 
En síntesis, desde la libertad se asume la condición humana reconociendo la limitación y la posibilidad de la plenitud humana. La razón concede que desde la humildad y la obediencia se acometen los grandes proyectos.

Por otro lado, el proceso personal de conocimiento necesita, también, la ayuda de los otros (38). Un adecuado acompañamiento y una dirección espiritual (39) capacitada (40) posibilitan la orientación de la vida hacia el conocimiento y la obediencia (41). El ser humano formándose y contrastándose, se habilita para la voluntad de Dios, teniendo como modelo al Hijo que sufriendo aprendió a obedecer $(\mathrm{Hb} 5,8)$. El testimonio es estímulo para el avance en el proceso, pretendiendo lo imposible y lanzándose a lo elevado (42).

En esta etapa no hay que exponerse a riesgos innecesarios ya que se sabe la propia fragilidad; a ello ayuda el permanente estudio contrastado con expertos. Conociendo la flaqueza humana, la inmadurez por falta de experiencia, es posible que se eviten las dificultades que van surgiendo así como la caída. El ser humano se fascina y, pretendiendo lo que le sobrepasa, cae en la tentación de querer ser como Dios. El desarrollo en el proceso de madurez requiere la fortaleza en el sufrimiento (43). El reconocimiento de la acción de Dios empujando a plenitud, alienta el camino interior sabiendo del riesgo de retroceso; y ayuda a evitar el pecado y favorecer la gracia, que ha conducido hasta este momento existencial (44).

El dilema se plantea entre el avance en el camino bajo obediencia o la vuelta atrás por la caída en la tentación. El deseo es el seguimiento de Jesucristo, irse configurando a Él, aprendiendo a obedecer; pero la realidad parece volverse en contra. Por ello, se retorna muchas veces a estas moradas, porque la tentación es grande, fuerte, poderosa, y gana al esfuerzo humano que, únicamente se fortalece con el sufrimiento y el mucho padecer (45). En síntesis, la razón, enriquecida por el conocimiento que los otros aportan, cuida las ocasiones de tentación porque sabe de

(38) Cf. 3M 2, 12.

(39) Ib., "aunque no sean religiosos, sería gran cosa, como lo hacen muchas personas, tener a quien acudir para no hacer en nada su voluntad...".

(40) Ib., "procurar quien esté con mucho desengaño de las cosas del mundo, que... y no buscar otro de su humor, como dicen, que vaya con tanto tiento en todo, sino".

(41) Ib., "nos haría mucho provecho... tratar con quien ya le conoce para conocernos... estudiar mucho en la prontitud de la obediencia".

(42) Ib., "y porque algunas cosas que nos parecen imposibles, viéndolas en otros tan posibles y con la suavidad que las llevan, anima mucho... y parece que con su vuelo nos atrevemos a volar, como hacen los hijos de las aves cuando se enseñan que, aunque no es de presto dar un gran vuelo, poco a poco imitan a sus padres".

(43) Ib., "En gran manera aprovecha esto; yo lo sé. Acertarán, por determinadas que estén en no ofender al Señor personas semejantes, no se meter en ocasiones de ofenderle; porque, como están cerca de las primeras moradas, con facilidad se podrán tornar a ellas; porque su fortaleza no está fundada en tierra firme, como los que están ya ejercitados en padecer, que conocen las tempestades del mundo cuán poco hay que temerlas ni que desear sus contentos y sería posible con una persecución grande volverse a ellos, que sabe bien urdirlas el demonio para hacernos mal, y que, yendo con buen celo, queriendo quitar pecados ajenos, no pudiese resistir lo que sobre esto se le podría suceder".

(44) Ib., "haría mucho provecho a las que por la bondad del Señor están en este estado -que, como he dicho, no les hace poca misericordia porque están muy cerca de subir a más-...".

(45) Cf. Martín Velasco, J., La experiencia cristiana de Dios, 2. ed., Madrid, Editorial Trotta, 1996, 170-173. Teresa hasta los 39 años se enfrentaba con esta realidad. 
la fragilidad. Se fortalece en el sufrimiento, tratando de configurarse a Cristo, para lanzarse hacia la plenitud humana.

En tercer lugar, un breve atisbo de la razón que afronta el dilema, desde la libertad en relación con los semejantes, y descubre la limitación como medio para la profundidad (46). Del mismo modo que la esposa del Cantar $(8,1-4)$, el hombre desea ser llevado, donde nadie le minusvalore y disfrute de Dios (47). Hay una tensión interior rompedora: la gran lucha entre la pequeñez humana y la aspiración a lo divino; el desprecio por la flaqueza, que habita el interior como impedimento, frente a la experiencia de lo ansiado, que finalmente se concede en el estado de unión (48). En este momento de quiebre entre lo ascético y lo místico, se vive con gran dificultad la tensión entre el deseo y la realidad. El propio hombre es obstáculo para el reposo: vive interiormente tal desasosiego que no puede acogerse a sí mismo (49). Por otro lado, conocer donde Dios mora genera paz y alegría. El dilema se puede resolver en la profundidad humana: allá habita lo divino y se alberga la debilidad humana. Así, la razón afronta el dilema entre la pequeñez humana y la aspiración a lo divino; el dilema entre la lucha del cada día y el sosiego del abandono en Dios.

En definitiva, la razón libre reconoce la limitación; se cuida de las ocasiones de tentación y se fortalece en las pruebas, sabiendo que la flaqueza habita en lo más profundamente humano, junto con la presencia oculta de Dios.

\subsection{Libertad referida a la transcendencia}

El dilema existencial genera frutos cuando la razón liberada se lanza más allá de sí misma. Se aborda la salvación $(3 \mathrm{M} 1,1)$ y la diferencia entre contento y gusto $(4 \mathrm{M} \mathrm{1,4).}$

La salvación es iniciativa de Dios y necesita la cooperación humana, por eso genera incertidumbre, aunque, también, certeza (50). El ser humano va trabajando su vida con actitudes fundamentales: la permanencia en la lucha, la constancia en el esfuerzo, la gratuidad de la bienaventuranza (51). La misericordia de Dios va dando seguridad al hombre que vive en esta etapa de ambigüedad, llegando a la certeza de la salvación si ratifica la decisión del seguimiento de Jesús (52). Ante el dilema de la certeza o la incertidumbre de la salvación, se responde que es en la acción conjun-

(46) Cf. 4M 1, 12.

(47) Ib., "Conozcamos nuestra miseria, y deseemos ir adonde nadie nos menosprecia...".

(48) Ib., “¡llévanos, Señor, adonde no nos menosprecien estas miserias que parecen algunas veces que están haciendo burla del alma! Aun en esta vida la libra el Señor de esto, cuando ha llegado a la postrera morada, como diremos, si Dios fuere servido".

(49) Ib., "que quiera el Señor aparejarnos el descanso y que en nosotras mismas esté el estorbo, no puede dejar de ser muy penoso y casi insufridero".

(50) Cf. $3 \mathrm{M} 1,1$

(51) Ib., "A los que por la misericordia de Dios han vencido estos combates y con la perseverancia entrado a las terceras moradas, ¿qué les diremos, sino bienaventurado el varón que teme al Señor? (Sal 111, 1)".

(52) Ib., "No ha sido poco hacer su Majestad que entienda yo ahora qué quiere decir el romance de este verso a este tiempo... pues si no torna atrás, a lo que podemos entender, lleva camino seguro de su salvación...”. 
ta de Dios y el hombre donde acontece la certeza: el esfuerzo humano y el don gratuito de Dios.

El camino de seguimiento a Jesús está relacionado con el camino que cada hombre recorre en el autoconocimiento. La duda de la salvación es permanente; pues aunque la oferta es universal (Lc 13, 22-30), depende de la libertad humana que juzga y discierne adecuado un determinado camino (53). El Dios del amor llama a todos al seguimiento, el hombre duda y se confunde eligiendo la puerta ancha. El dilema se aboca a un proceso de discernimiento que le haga partícipe de la salvación. La razón se ratifica en la seguridad de la salvación si avanza en el proceso, aun sabiéndose capaz de la ofensa, del abandono y de la infidelidad al proyecto de Dios. El Dios misericordioso llama a todos, el hombre libremente decide; por eso es fundamental un acertado discernimiento (54).

Llegando a este punto, en el capítulo primero de las cuartas moradas, lugar de quiebre, se anuncia la diferencia entre contento y gusto (55). La razón se alegra con los logros conseguidos; admite que el natural del hombre se contente por lo bueno realizado, con la obra bien hecha. El gozo humano, natural, se experimenta tanto en la relación personal (encuentro con el amado, a quien se creía muerto), como en las tareas que acarrean complacencia (la posesión de bienes materiales: propiedades, fama, dinero, etc.) (56).

El contento corresponde a un logro de la acción del hombre (57), y el gusto es una realidad procedente de Dios (58). Los gustos son contentos más elevados: "de linaje más noble" (59). El ser humano, referido a la transcendencia y en búsqueda de la salvación, experimenta la alegría por las cosas de Dios. Es una experiencia de

(53) Ib., "con la perseverancia entrando a... lo que importa vencer las batallas pasadas, ... (y) no torna a dejar el camino comenzado".

(54) Cf. Orbe, A., "El dilema entre la vida y la muerte", Gregorianum 51 (1990) 305-365 (I parte) y 509-536 (II parte). Se estudia Dt 30,15.19. El autor señala: "El Señor no se contenta con poner al individuo en la alternativa de vida y muerte, indiferente El y neutral ante la humana decisión. Las dos partes de Dt 30, 19 se completa. A la propuesta inicial -"Yo te pongo delante la vida y la muerte, la bendición y la maldición"- sigue el consejo divino: "Escoge pues la vida, a fin de que vivas tú y tu descendencia”. El consejo iba implícito en los términos de la propuesta. Nadie que llame muerte o maldición a uno de los extremos, y vida o bendición al otro, deja de reflejar su pensamiento. No es solo consejo. San Ireneo descubrirá en él un precepto, el Decálogo. La libertad, don de Dios al hombre, se ordena a la vida feliz. El cielo no atenta contra el libre albedrío, por ordenar un extremo de la alternativa, en bien del interesado. Salva lo necesario y suficiente para el mérito" (307).

(55) Cf. 4M 1, 4.

(56) Ib., "con razón nos da contento habernos empleado en cosas semejantes. Mas, si lo consideramos, los mismos contentos tendremos en muchas cosas que nos pueden suceder en la tierra, así en una gran hacienda que de presto se provea alguno, como de ver una persona, que mucho amamos, de presto; como de haber acertado en un negocio importante y cosa grande de que todos dicen bien; como si a alguna le han dicho que es muerto su marido o hermano o hijo y le ve venir vivo".

(57) Ib., "adquirimos con nuestra meditación y peticiones a nuestro Señor, que procede de nuestro natural, /.../, mas nacen de la misma obra virtuosa que hacemos y parece a nuestro trabajo lo hemos ganado".

(58) Ib., "comienzan de Dios y siéntelos el natural y goza tanto de ellos como gozan los que tengo dichos y mucho más".

(59) Ib., "Yo he visto derramar lágrimas de un gran contento y aun me ha acaecido alguna vez. Paréceme a mí que, así como estos contentos son naturales, así en los que nos dan las cosas de Dios, sino que son de linaje más noble, aunque estotros no eran tampoco malos" 
cumplimiento del Reino en el cada día. El movimiento del hombre a Dios, contento, se ve enriquecido y potenciado por la acción de Dios que llega al ser humano como gozo mayor, el gusto. Se requiere la permanencia en la unión con Dios: solamente da fruto el sarmiento que permanece unido a la vid (60).

Se explica la diferencia entre contento, la alegría vivida por la fidelidad al proyecto de Dios, y el gusto que es la alegría recibida gratuitamente de Dios. Desde una clara conciencia de las limitaciones se pide al Señor la iluminación, y la autora entra en el campo teórico de formulaciones de las experiencias interiores: Dios siempre actúa en el hombre y el fruto nace, únicamente, si el hombre permanece en el Señor. En la relación de Dios con el hombre, la pequeñez se une con la grandeza y se va dando la transición de la vida ascética a la mística (61).

El dilema se resuelve en la apuesta por lo más grande, ambos elementos son medios, en las diversas etapas, para el camino hacia la plenitud. La alegría, también, tiene su dilema: alegría producida porque se realizan las cosas de Dios y la alegría otorgada al hombre por Dios. El ser humano se va plenificando en la colaboración con Dios y en la apertura a su acción, y la razón se alegra por las metas logradas. El gozo se experimenta porque el Reino se va concediendo, el contento, intensificado por la acción de Dios se transforma en gusto; la persona se hace más humana. La teología de Teresa es una escatología realizada en el hoy y en la persona. En definitiva, la razón liberada se experimenta cuando el hombre buscando con incertidumbre la salvación $(3 \mathrm{M} 1,1)$, recibe con certeza el gusto, aquello que no esperaba conseguir y le desborda $(4 \mathrm{M} 1,4)$.

\section{El amor como ámbito de creatividad}

El dilema existencial fundamental se hace fecundo en la creatividad del amor. El dilema, gracias al amor, se amplia, se dilata y acoge todo lo que lleve a mayor plenitud. La creatividad del amor posibilita que el dilema, encorvarse o abrirse, se enriquezca integrando todo lo que recibe desde las relaciones en la historia.

\subsection{Las relaciones interpersonales iluminan el dilema humano}

El amor ensancha el entendimiento (prol 4) para la comprensión, incluso, del amor de Dios (1M 1,3). La comunicación de la experiencia de Dios conduce al amor por los demás, en quienes se ama a Dios, y eso plenifica al hombre $(1 \mathrm{M} 1,4)$.

La autora en Las Moradas del Castillo Interior parte con realismo, reconociendo la limitación y la carencia de pretensiones, y, junto a ello, la confianza en que Dios posibilita la obra (62).

Desde el comienzo, expone las razones del atrevimiento para la escritura y el método que utiliza. Deja claro que es Dios quien la mueve y quien, en definitiva,

(60) Ib., "que hase de entender en cuanto dijere que no podemos nada sin él... aunque en fin ayuda para ello Dios, ... no podemos nada sin él”. Se hace referencia a Jn 15, 5.

(61) Ib., "¡Oh Jesús, y qué deseo tengo de saber declararme en esto!; porque entiendo, a mi parecer, muy conocida diferencia y no alcanza mi saber a darme a entender; ¡hágalo el Señor!”.

(62) Cf. Prólogo 4. 
guía esta empresa. Cuatro son las razones que motivan su tarea: la obediencia, la docencia, la identidad y la relación. Cada una de ellas manifiesta y expresa la humildad y la salvaguarda de cualquier atisbo de arrogancia. La obediencia a los superiores es el argumento que aclara la ausencia de engreimiento y otorga la responsabilidad a otros (63). La necesidad de la docencia es el objetivo que la mueve; ante la carencia de otros ve la posibilidad y la urgencia de dar luz en aspectos de la vida interior (64). No parte de ella, sino que se sitúa como instrumento disponible y al servicio del bien de los otros. En tercer lugar, aprovecha y valida su identidad de mujer, en un contexto sociocultural-eclesial y en una época, también, de serios obstáculos para que la mujer enseñe sobre oración (65). Finalmente, la buena relación con los oyentes, facilita la comprensión. En su caso, se da la conexión de amor entre mujeres: el trato teñido por un cierto universo teórico, el compartir un similar ámbito experiencial, y una común sintonía, ayuda al entendimiento (66). Consciente de su labor de escritora explica su método (67).

Teresa afirma que escribe por obediencia, para aclarar dudas, como mujer querida y amada, y desde un peculiar estilo literario. Pero, además, se cobija bajo la acción protectora de Dios; sabe por experiencia que su empeño servirá, únicamente si Dios quiere. Se declara instrumento del Señor; es consciente de la acción de Dios dentro de la condición humana (68). El amor de Dios en la creatura posibilita la desmesurada tarea de desvelar el misterio divino. De este modo, se revela la grandeza de Dios y la pequeñez humana: Dios y el ser humano en armonía. El hombre aporta razones y busca maneras; reconoce la humilde condición y, desde la limitación asumida, emprende trabajos que le superan. El ser humano anclado en Dios y sostenido por Él se capacita para la transmisión del misterio y eso genera la alabanza (69).

El dilema se plantea entre la incapacidad o la posibilidad humana para el acceso al misterio de Dios y del hombre. Consciente de esta gran disyuntiva aporta su valiosa y acertada respuesta: es posible el cumplimiento de la encomienda de colmar lo humano. Esa plenitud se vive comunicando la gran experiencia de saberse y vivirse habitada por Dios y habitando en Dios. Esta misión la cumple, también, a través de la obra escrita. El dilema resuelto de este modo muestra como la capacidad humana del amor, don de Dios, posibilita la ampliación del entendimiento racional.

(63) Ib., "Díjome quien me mandó escribir que". El tema de la obediencia en Santa Teresa se puede consultar en García de la Concha, V., Al aire de su vuelo, Barcelona, Círculo de lectores, 2004, $22-26$.

(64) Ib., "estas monjas de estos monasterios de nuestra Señora del Carmen tienen necesidad de quien algunas dudas de oración las declare y que...".

(65) Ib., "le parecía que mejor se entienden el lenguaje unas mujeres de otras y".

(66) Ib., "que con el amor que me tienen les haría más al caso lo que yo les dijere, tiene entendido por esta causa será de alguna importancia, si se acierta a decir alguna cosa”.

(67) Ib., "y por esto iré hablando con ellas en lo que escribiré". Resulta que este camino es el inicio de una manera novedosa en la literatura del siglo XVI español. Se atreve a no seguir los cánones convencionales y así se libera de un montón de normas establecidas. Desde el comienzo defiende su propio estilo que acaba siendo original, libre y novedoso.

(68) Ib., "Bien sabe su Majestad que /... / parece desatino pensar que puede hacer al caso /... / harta merced me hará nuestro Señor si a alguna de ellas se aprovechare para alabarle algún poquito más".

(69) Ib., "no pretendo otra cosa; /... / cuando algo se atinare a decir, / .. / el Señor por su misericordia (no) la da". 
A modo de síntesis, el acceso al conocimiento se produce con mayor prontitud desde el amor (Prólogo 4). La humildad, el deseo de aprendizaje, la asunción de la propia identidad, y la empatía son actitudes adecuadas para las relaciones, liberadas de prejuicios, que generan el ensanchamiento de la razón gracias al amor.

En un segundo momento, se estudia el amor al prójimo que abre al entendimiento del amor de Dios (70).

Las relaciones interpersonales iluminan el entendimiento del hombre; se llega a la comprensión del amor de Dios cuando se ama al prójimo. Este punto inicial de la obra, presenta la imagen que usa a lo largo de todo el libro: el castillo con muchas moradas. A continuación, explica la acción de Dios junto con las posibilidades y dificultades de su comprensión. Termina afirmando la certeza del amor de Dios en el hombre que ama. En el centro del castillo acontece la relación humano divina: la autocomunicación de Dios posibilita el amor humano (71). Sabiendo de la imposibilidad del conocimiento del misterio de Dios (72), se intenta explicarlo como presencia que se comunica desde lo profundo de la persona (73).

La certeza del amor de Dios se alcanza cuando se ama al prójimo. El hombre encorvado sobre sí mismo, engreído y egoísta, no comprende la gracia de Dios (74). Sin embargo, saliendo de sí, se dispone a la apertura del recibimiento, se alegra porque descubre que Dios da a entender su misterio (75). Se pone en juego la libertad: el acceso al misterio de Dios es gracia concedida a quienquiera recibirla. Quien acoge libremente el don de Dios se transforma, deja de ser ciego (Jn 9, 2), y manifiesta en él mismo "las obras de Dios" (Jn 9, 3) (76). La persona experimenta un cambio fundamental; se ve la realidad de manera nueva. Es la conversión que transforma a Pablo y Magdalena en seguidores de Jesús. La gratuidad de Dios concede el acceso al misterio y la persona agradece tanto derroche (77).

(70) Cf. 1M 1, 3 .

(71) Ib., "Pues consideremos que este castillo tiene, como he dicho, muchas moradas: unas en lo alto, otras en bajo, otras a los lados; y en el centro y mitad de todas estas tiene la más principal, que es adonde pasan las cosas de mucho secreto entre Dios y el alma". Cf. 1Jn 4, 7.8.16: "Queridos, amémonos unos a otros, ya que el amor es de Dios, y todo el que ama ha nacido de Dios y conoce a Dios. Quien no ama no ha conocido a Dios, porque Dios es Amor. /.../ Y nosotros hemos conocido el amor que Dios nos tiene, y hemos creído en él. Dios es Amor y quien permanece en el amor permanece en Dios y Dios en él".

(72) Ib., "pueda por ella daros algo a entender de las mercedes que es Dios servido hacer a las almas y las diferencias que hay en ellas, hasta donde yo hubiere entendido que es posible; que todas será imposible entenderlas nadie, según son muchas, ¡cuánto más quien es tan ruin como yo!”.

(73) Ib., "os será gran consuelo, cuando el Señor os las hiciere, saber que es posible; y a quien no, para alabar su gran bondad... que así como no nos hace daño considerar las cosas que hay en el cielo y lo que gozan los bienaventurados, antes nos alegramos y procuramos alcanzar lo que ellos gozan, tampoco nos hará ver que es posible en este destierro comunicarse un tan gran Dios... y amar una bondad tan buena y una misericordia tan sin tasa".

(74) Ib., "a quien hiciere daño entender que es posible hacer Dios esta merced en este destierro, que estará muy falta de humildad y del amor del prójimo".

(75) Ib., "porque, si esto no es, ¿cómo nos podemos dejar de holgar de que haga Dios estas mercedes a un hermano nuestro, pues no impide para hacérnoslas a nosotras, y de que su Majestad dé a entender sus grandezas, sea en quien fuere?".

(76) Ib., "Que algunas veces será solo por mostrarlas, como dijo del ciego que dio vista, cuando le preguntaron los apóstoles si era por sus pecados o de sus padres (Jn 9, 2-3)”.

(77) Ib., "Y así acaece no las hacer por ser más santos a quien las hace que a los que no, sino porque se conozca su grandeza, como vemos en san Pablo y la Magdalena, y para que nosotros le alabemos en sus criaturas". 
Se afirma la autocomunicación de Dios que posibilita la autonomía humana (78). Dios se acerca, se aproxima, se anonada y se comunica al ser humano. No hay dicotomía, ni elección entre ser humano o Dios, sino comunión y descenso, proximidad de Dios al hombre que dignifica, humaniza y cambia para el amor. Dios otorga el don, se acerca al hombre sin anularlo; así se empieza a atisbar el misterio transcendente. Esto es posible desde la humildad, sin pretensión de ser Dios, y en la entrega al prójimo. Se comprende el misterio de Dios, en el amor humano, y esto posibilita la dirección hacia la experiencia de la transcendencia. Las relaciones interpersonales son fuente de creatividad humana. En el amor al otro el ser humano se transciende, supera su dilema congénito de autorreferencialidad y se crea a sí mismo. Las relaciones interpersonales iluminan la comprensión humana. Se entiende el amor de Dios desde el amor al prójimo.

Dios habita y se comunica en la hondura humana; allí se adhiere al conocimiento experiencial desde la humildad y el amor. Se da la paradoja de que al centro más interior, se llega descentrándose y saliendo de sí. Desde esa libre apertura se recibe la revelación gratuita de Dios que opera la conversión. El dilema entre Dios o el hombre se transforma en la manifestación de Dios en el hombre. En las relaciones amorosas se descubre y se comprende la misteriosa acción divina.

Un tercer elemento, estudiado por Teresa respecto a que las relaciones interpersonales iluminan el dilema humano, es descubrir que la comunicación de la experiencia de Dios conduce al amor (79).

Se invita al diálogo y la comunicación, con mesura y sin escandalizar (80), de las misericordias de Dios porque no hace mal a los débiles y ayuda a los creyentes (81). Además, provoca, incluso, la apertura del hombre no creyente al amor. Por supuesto, para el creyente, que sabe del amor de Dios, es un gran estímulo para la fe y el crecimiento en el amor (82).

La creencia en el Dios del amor conduce a la experiencia de un amor desmedido. La afirmación por la cual, únicamente, el creyente consiente a la experiencia de Dios, no es una exclusión sino una consecuencia de la libertad humana y divina. Dios manifiesta su libertad y acepta la libertad humana: no se deja manejar, y tampoco se impone al no creyente (83). Cuando el hombre no cree, Dios no apabulla pues su acción es discreta; cuando el hombre cree, Dios revela sus maravillas. La libertad de Dios respetando a la creatura se muestra, por un lado, en la ausencia de imposición y en la no evidencia aplastante de su acción; y por otra parte, en la transformación del ser humano para el amor, pues la tarea amorosa, como la fe, no

(78) Ib., "es posible en este destierro comunicarse un tan gran Dios con unos gusanos tan llenos de mal olor".

(79) Cf. 1M 1, 4.

(80) Ib., "Podráse decir que parecen cosas imposibles y que es bien no escandalizar los flacos".

(81) Ib., "Menos se pierde en que ellos no lo crean que no en que se dejen de aprovechar a los que Dios las hace se regalarán y despertarán a más amar a quien hace tantas misericordias, siendo tan grande su poder y majestad...”.

(82) Ib.,: "cuánto más que sé que hablo con quien no habrá este peligro, porque saben y creen que hace Dios aun muy mayores muestras de amor...".

(83) Ib.,: "Yo sé que quien esto no creyere no lo verá por experiencia, porque es muy amigo de que no pongan tasa a sus obras...". 
nace espontáneamente (84). En el terreno de las relaciones interpersonales, la comunicación y la fe, sostenidas en la confianza, dan plenitud al ser humano que se transciende a sí mismo en la relación con los otros y con el Otro.

En este texto se detecta un par de dilemas. El primero se plantea entre el callar para no escandalizar, al comienzo del texto, frente a comunicar para despertar y crecer en el amor. El segundo dilema hace referencia al tema de la fe: creer o no creer, se pone en juego la libertad. La acción de Dios consiente en la decisión humana, no hay demostración de la existencia de Dios al margen de la libertad de la creatura. La creencia es apuesta y riesgo y así se comprueba la libertad humana. La resolución de ambos dilemas es a través de la comunicación, haciendo a otros partícipes de la propia experiencia de fe, transmitiendo el amor de Dios, se ayuda al que lo comparte y, también, puede generar amor en quien recibe el testimonio existencial. En el proceso de comunicación ocurre la apertura a lo otro y al amor, es decir, la transmisión del conocimiento experiencial de Dios y sus dones, libremente concedidos y aceptados, conduce al amor.

\subsection{Las relaciones con Dios otorgan conocimiento para amar}

El conocimiento personal y de Dios $(1 \mathrm{M} 2,17)$ encaminan hacia el amor al prójimo, la plenitud (85) (1M 2, 18).

La comprensión de sí para amar al prójimo y a Dios es la auténtica perfección (86). Se desarrolla en tres ideas centrales: el amor al prójimo puede debilitarse (87); la auténtica perfección consiste en el amor al prójimo y a Dios (88); y, en tercer lugar, el conocimiento personal se realiza sin comparaciones (89).

Entenderse a sí mismo y a los demás y el conocimiento de Dios conduce a amarse a sí mismo, amar a los otros y a Dios. Es decir, el conocimiento conduce a la perfección del amor (90). Este amor se alimenta de la profundidad de la existencia humana, y en el camino encuentra impedimentos, el más grave y detectable es la envidia (91).

(84) Ib., "a quien hace tantas misericordias, siendo tan grande su poder y majestad; cuánto más que sé que hablo con quien no habrá este peligro, porque saben y creen que hace Dios aun muy mayores muestras de amor ... y así, hermanas, jamás os acaezca a las que el Señor no llevare por este camino".

(85) Cf. Lubac, H., de, Paradoja y misterio de la Iglesia, Salamanca, Ediciones Sígueme, 1967, 183 214. La razón la tiene la sencillez efectiva del amor. Los hombres no pueden amarse sin Dios. El hombre solo puede ser amado en Dios. Dios solo puede ser amado en el hermano. Así lo expresa De Lubac, comentando a H.U. von Baltasar.

(86) Cf. $1 \mathrm{M} \mathrm{2,17.}$

(87) Ib., "Lo que aquí pretende el demonio no es poco: que es enfriar la caridad y el amor de unas con otras, que sería gran daño".

(88) Ib., "Entendamos, /.. / y, mientras con más perfección guardáremos estos dos mandamientos, seremos más perfectas. Toda nuestra Regla y Constituciones no sirven de otra cosa sino de medios para guardar esto con más perfección".

(89) Ib., "Dejémonos de celos indiscretos que nos pueden hacer mucho daño; cada una se mire a sí. Porque en otra parte os he dicho harto sobre esto, no me alargaré".

(90) Ib., "Entendamos, hijas mías, que la perfección verdadera es amor".

(91) Ib., "enfriar la caridad y el amor de unas con otras, que sería gran daño ... Dejémonos de celos indiscretos que nos pueden hacer mucho daño; ... cada una se mire a sí ...”. 
El ser humano ante sí mismo se enfrenta a la autenticidad o la falsedad. El dilema enfrentado en las relaciones humanas se refleja en: envidia o generosidad; rivalidad o confianza; comparaciones o gratuidad. Y cuando el ser humano se refiere a Dios: perfección o imperfección. La superación de estos dilemas se hace apostando por la autenticidad del yo; por la generosidad y la confianza; y la aspiración al amor (92). En definitiva, conocerse a sí mismo, sin comparaciones, conduce al amor al prójimo, de modo vigilante y permanente; y conduce al amor a Dios, lo máximo a que el hombre tiende.

El amor al prójimo colma porque (93): es camino de plenitud (94); fortalece los valores (95); y cultiva la silenciosa sensatez (96).

La plenitud puede malograrse por simplicidades. Una de ellas es vivir pendientes de los errores ajenos que llevan al desasosiego (97). La fijación en los defectos ajenos es una solicitación al pecado, por eso recomienda la prudencia (98). Por otro lado se invita a la crítica a los demás, practicando con sensatez la corrección fraterna (99). Estas advertencias se encaminan a la solidez de los cimientos, a la fortaleza

(92) Ib., "la perfección verdadera es amor de Dios y del prójimo".

(93) Cf. 1M 2, 18. Cf. Lubac, H., de, Paradoja y misterio de la Iglesia, Salamanca, Ediciones Sígueme, 1967, 193. De Lubac pregunta ¿cómo podría el hombre amar al hombre? Lo único que puede hacer, es "morir de sofocación" a su contacto. "Si en los demás no existe más que lo que cada uno de nosotros conocemos a fondo por nosotros mismos -un ser con las limitaciones inherentes a su naturaleza, angustiado por sus límites, chocando inopinadamente con ellos: enfermedad, locura, azares del destino; un ser a quien la angustia puede darle alas para realizaciones sorprendentes-, entonces ¿por qué mi "yo" tendría que perderse por un "tú", al que no puede estimar más que a sí mismo, en su nivel más profundo? Pero no es así, ciertamente. Si en mi ambiente no me encuentro con Dios, si en el amor no existe ninguna brisa que me traiga el perfume de lo infinito, si no puedo amar al prójimo con un amor que sea superior a mi poder limitado de amar, si, en nuestro encuentro eso que se llama el altísimo nombre de amor no viene de Dios y no vuelve a Dios, no vale la pena que intente tamaña aventura. No se librará con ella el hombre de su prisión ni de su soledad ... los hombres no pueden amarse sin Dios". Sigue De Lubac comentando a Von Balthasar y dice que en este momento histórico se ha hecho evidente que el hombre solamente puede ser amado en Dios, y que Dios no es amado más que en "el sacramento del hermano". Es hora de reconocer que "todo amor cristiano implica un rompimiento de los recintos cerrados ... una salida hacia los hermanos perdidos, hacia los enemigos...".

(94) Ib.,: "Importa tanto este amor de unas con otras que nunca querría que se os olvidase, porque de andar mirando en las otras unas naderías que a las veces no será imperfección, sino, como sabemos poco, quizá lo echaremos a la peor parte, puede el alma perder la paz y aun inquietar la de las otras; mirad si costaría caro la perfección".

(95) Ib.,: "También podría el demonio poner esta tentación con la priora y sería más peligrosa; para esto es menester mucha discreción, porque si fuesen cosas que van contra la Regla y Constitución es menester que no todas veces se eche a buena parte sino avisarla y, si no se enmendare, al prelado."

(96) Ib., "Esto es caridad; y también con las hermanas, si fuese alguna cosa grave. Y dejarlo todo por miedo si es tentación, sería la misma tentación. Mas hase de advertir mucho, porque no nos engañe el demonio, no lo tratar una con otra -que de aquí puede sacar el demonio gran ganancia y comenzar costumbre de murmuración- sino con quien ha de aprovechar, como tengo dicho. Aquí, ¡gloria a Dios!, no hay tanto lugar, como se guarda tan continuo silencio; más bien es que estemos sobre aviso".

(97) Ib., "naderías que a las veces no será imperfección, sino, como sabemos poco, quizá lo echaremos a la peor parte, puede el alma perder la paz y aun inquietar la de las otras".

(98) Ib., "También podría el demonio poner esta tentación... con la priora y sería más peligrosa, ... porque si fuesen cosas que van contra la Regla y Constitución... para esto es menester mucha discreción".

(99) Ib.,: "no todas veces se eche a buena parte sino avisarla y, si no se enmendare, al prelado. Esto es caridad; y también con las hermanas, si fuese alguna cosa grave". 
en los valores, para que el amor discierna la oportunidad del silencio y la necesidad de la denuncia.

La conversación en perjuicio de otros es una estrategia del mal, y separa dividiendo y socavando el amor (100). La corrección fraterna y la denuncia se realizan de manera adecuada, para que sea útil, sirva y ayude al crecimiento en el amor (101). Dios otorga la prudencia y la sabiduría para el cultivo del amor y eso genera la alabanza (102).

Se citan los dilemas siguientes: olvido o recuerdo; discreción o corrección; provecho o desahogo. Así, el descuido del amor lleva a la imperfección y a la murmuración, y la memoria del amor conduce a la perfección y no cuenta los errores ajenos; la evocación del amor produce paz y su descuido crea inquietud. Otra formulación del dilema es la discreción que nace de la sensatez y la prudencia, o la denuncia que pretende la corrección de lo dificultoso; se trata de la elección del silencio o el aviso. La persona vence la tentación y opta por la corrección fraterna, de modo que todo sea siempre para provecho del otro y no para desahogo personal. El amor es camino de perfección desde la corrección fraterna, el cultivo de actitudes prudentes y sabias, bendiciendo sin murmurar y el fomento del silencio respetuoso.

\subsection{La realidad cotidiana espacio para la vivencia de relaciones}

En este tercer apartado, del amor creativo, se ofrecen respuestas al dilema desde la iluminación del conocimiento en la historia concreta. El espacio de verificación de la creatividad del amor es la realidad cotidiana. En ella se expresan los frutos generados por el afrontamiento del dilema.

Así, la limitación, propia de la condición creatural, es base para el proceso de interiorización (4M 1, 10); y el límite se asume desde el amor de Dios (4M 1, 11), de tal manera que el amor atraiga hacia sí a la razón (4M 1,6).

La limitación no impide el camino interior (103). Incluso, en medio del tumulto, del escándalo de sonidos perturbadores (104), la persona vive en paz; dedicándose a la relación de amistad con el Señor y a la escritura. El sentido que se encuentra al sufrimiento, es que sea ocasión de mayor y mejor conocimiento (105). La asunción de la debilidad prepara para retos mayores. La persona unificada, vive bien lo cotidiano, en medio de un entorno alterado, crispado y tensionante; permanece en sosiego (106).

(100) Ib., "Mas hase de advertir mucho, porque no nos engañe el demonio, no lo tratar una con otra --que de aquí puede sacar el demonio gran ganancia y comenzar costumbre de murmuración".

(101) Ib., "sino con quien ha de aprovechar, como tengo dicho".

(102) Ib., "igloria a Dios!, no hay tanto lugar, como se guarda tan continuo silencio; más bien es que estemos sobre aviso".

(103) Cf. 4M 1, 10.

(104) Ib., "están en ella muchos ríos caudalosos y por otra parte que estas aguas se despeñan; muchos pajarillos y silbos, ...".

(105) Ib., "no será mucho que haya querido el Señor darme este mal de cabeza para entenderlo mejor; porque con toda esta baraúnda de ella no me estorba a la oración ni a lo que estoy diciendo, ...".

(106) Ib., "sino que el alma se está muy entera en su quietud y amor y deseos y claro conocimiento". 
El amor de Dios ayuda a la convivencia con la limitación, el dolor y el desorden del pensamiento (107). En este momento aunque no tiene explicaciones claras, expresa la necesidad del esfuerzo humano para que el pensamiento no desestabilice, ni turbe, y pase pronto. Además, especialmente, el amor de Dios capacita con la paciencia ante la condición personal, y afirma la voluntad: nada puede separar del amor de Dios (Rm 8, 35-37). Mucho menos se amedrenta por las flaquezas del pensamiento.

El amor conduce a la razón de la meditación a la contemplación, se explica la diferencia entre contento y gusto (108). En la cuarta morada se sitúa el paso a la otra orilla; progresivamente señala las distintas etapas de la vida, y en esta adviene un gran cambio. Después de una vida intensa durante las tres moradas anteriores se llega a la cima, se vislumbra un quiebre hacia la otra vertiente. En la cumbre se descubre que los contentos se dan en la meditación y los gustos en la contemplación; y al señalar el punto de intersección se anima a la relación con Dios. El empeño humano y los deseos de progreso se interceptan y es necesario el avance. El amor estimula a la razón a progresar de lo meditativo y discursivo a la contemplación. Esto es, de pensar la pasión, a contemplarla alabando; holgándose en la bondad, y deseando la gloria y la honra del Señor.

Se plantea el dilema de volver atrás o pasar a la otra vertiente. La vida en las moradas anteriores donde prevalece el esfuerzo discursivo, el empeño del entendimiento; o una existencia acorde al proceso evolutivo de la persona entrando en la órbita de Dios, y consintiendo en el gozo del amor.

\section{EL DILEMA SE TRANSFORMA}

El principal dilema humano, encorvarse por el peso de lo acumulado, o abrirse para la donación de lo recibido, se transforma a través de la compenetración de amor y razón. El dilema se afronta acogiendo el proyecto de Dios y en la entrega por el Reino. La transformación del dilema se opera en la integración de elementos dispares y paradójicos.

\section{Compenetración de amor y razón: la gratuidad}

El dilema, acumular o entregar, se transforma cuando la gratuidad va impregnando la razón y el amor. Esto acontece cuando el conocimiento ama y el amor conoce; la razón se transforma en amorosa y el amor razona. La disyuntiva se hace conjuntiva; de la "o" se pasa a la "y", que junta y une ambas realidades humanas.

Primeramente prevalece la razón. En el segundo apartado, la razón se abre al amor. Finalmente, el amor es deseado por la razón porque colma y sobrepasa el dilema.

(107) Cf. 4M 1, 11.

(108) Cf. 4M1, 6. 


\subsection{Primacía de la razón}

La razón reconoce lo limitado de la realidad y lo valioso del amor, y acepta que el premio esté en función del amor. El amor crece en virtud del aumento del conocimiento personal y la razón domina y está muy influenciada por la realidad del mundo.

La razón descubre la necesidad del sentido para plantearse la vida, y lo encuentra desde el amor. Este texto invita a la permanencia en el proceso, y habla de la relación entre la fe y las potencias del hombre (109).

El ser humano se debate entre el retroceso o el adelanto; y también la contraposición entre la pretensión y la realidad. La razón realista presenta como engaño las pretensiones humanas: descubre la falsedad de creer que lo mundano es nada, y la pretensión lo es todo. La capacidad dubitativa se presenta como desasosiego ante la complejidad de la realidad que acaba en la muerte, y no colma el ansia humana (110).

A continuación, la fe dadora de sentido, entra en relación con la memoria, la voluntad y el entendimiento (111). Así, la memoria evoca que todo es vanidad y acaba en la muerte: la ausencia de recuerdo en otros (112); la pérdida de todo éxito (113); y el ser comido por los gusanos (114). La voluntad apuesta por el amor desde el seguimiento de Jesús, sentido de la existencia: el hombre desbordado en su propia capacidad, decide el amor a lo perecible (115). El entendimiento (116) comprende: la necesidad de la amistad de Jesús (117); la urgencia de la conciencia del engaño de la realidad (118); la certeza de la paz interior (119); el gozo de las capacidades propias sin el deseo de lo

(109) Cf. 2M 1, 4.

(110) Ib.,: “¡Oh Jesús!, qué es la baraúnda que aquí ponen los demonios y las aflicciones de la pobre alma que no sabe si pasar adelante o tornar a la primera pieza, porque la razón por otra parte le representa el engaño que es pensar que todo esto vale nada en comparación de lo que pretende ...".

(111) Cf. Körner, R., "El papel de la razón en la mística sanjuanista”, en Actas del Congreso Internacional Sanjuanista, Ávila 23-28 septiembre 1991, IV Pensamientos, Ruta de Castilla y León 1993, 195-202. Interesante el tratamiento de la experiencia mística y el pensamiento racional en el contexto del conocimiento humano.

(112) Ib., "trayéndole presente la muerte de los que mucho gozaron estas cosas; que ha visto, como algunas ha visto súbitas, cuán presto son olvidados de todos".

(113) Ib., "como ha visto a algunos que conoció en gran prosperidad pisar debajo de la tierra y aun pasado por la sepultura él muchas veces".

(114) Ib., "y mirar que están en aquel cuerpo hirviendo muchos gusanos, y otras hartas cosas que le puede poner delante".

(115) Ib., "amar adonde tan innumerables cosas y muestras ha visto de amor y querría pagar alguna, en especial se le pone delante cómo nunca se quita de con él este verdadero amador, acompañándole, dándole vida y ser".

(116) Cf. Körner, R., "El papel de la razón en la mística ...", 198. El área del pensar se sitúa en el entendimiento, una de las potencias del alma junto con la memoria y la voluntad. El entendimiento es la potencia cognitiva que obra por razón e intelecto. La razón toma conciencia de lo percibido, deduce, interpreta y juzga, y el intelecto recoge todo lo percibido. La razón parte de datos que le proporciona el intelecto. El intelecto mira lo que la razón le proporciona por su discurrir. Juntos "entendimiento y razón", acorde a la finitud del hombre, preparan el conocimiento y la experiencia humana.

(117) Cf. 2M 1, 4: "darle a entender que no puede cobrar mejor amigo".

(118) Ib., "todo el mundo está lleno de falsedad, y estos contentos, que le pone el demonio, de trabajos y cuidados y contradicciones".

(119) Ib., "y le dice que esté cierto que fuera de este castillo no hallará seguridad ni paz". 
externo (120); y, en quinto y último lugar, valora y agradece todo lo recibido, sobre todo la presencia de Dios en el hombre, y no mendiga despojos, como el hijo pródigo (121).

El trasfondo de esta reflexión teresiana plantea dilemas humanos serios. La primera disyuntiva consiste en la regresión al principio o la prolongación del camino. Es un dilema permanente que pone en juego, la realización plena de lo humano. Se descubre un segundo dilema entre la pretensión o la realidad. La realidad es provisoria, y permanente la pretensión. Frente a lo pasajero se ofrece la constante presencia de Dios. En este dilema, es posible la aceptación de la realidad con su fugacidad, medio al mismo tiempo, para el acceso a lo profundo donde se da la firme y constante duración. Es una conquista luchando en las distintas moradas para la definitividad. Finalmente, el dilema se concentra en el sentido o sin sentido de la existencia. El sentido nace de una fe que razona, comprendiendo el amor como la dirección apropiada para la realización humana, y que se opone al abocarse de todo a la muerte. La memoria hace presente la muerte del hombre; la voluntad se decide por el amor a la realidad y al amador; y el entendimiento presenta la falsedad del mundo. Si se hace un acercamiento desde la razón, se descubre la limitación de la realidad, y el engaño de minusvalorarla frente a la pretensión; pero también se descubre que la pretensión dilata y estira la precaria realidad. Si la aproximación es desde la perspectiva del amor, este impulsa a la profundidad en la limitada realidad.

Abordando la globalidad del ser humano, se afirma que la razón, consciente de las limitaciones y pretensiones-anhelos en pugna, apuesta por el amor a la realidad y por el amor al dador de la vida y el ser.

La razón acepta que el premio esté en función del amor que se practica. En la tercera morada, se invita a la vigilancia para conocerse y seguir, con determinación, el camino del amor (122).

El conocimiento de la hondura humana ayuda al discernimiento del auténtico dolor y sufrimiento, de la mera queja sin motivo. La desazón refleja la falta de humildad de quien concede demasiada importancia a sequedades pero puede ser ocasión para la vigilancia (123). La venta de lo poseído es el primer paso para el despojo, el desasimiento, el seguimiento propuesto por el Señor; y después, se camina hacia el adentramiento en sí, en la realidad, en los otros y en Dios. Sin vaciamiento no hay seguimiento, no hay capacidad para el amor (124).

(120) Ib., "que se deje de andar por casas ajenas, pues la suya es tan llena de bienes, si la quiere gozar".

(121) Ib., "que ¿quién hay que halle todo lo que ha menester como en su casa, en especial teniendo tal huésped que le hará señor de todos los bienes, si él quiere no andar perdido, como el hijo pródigo, comiendo manjar de puercos? (Lc 15, 16)".

(122) Cf. 3M 1, 7.

(123) Ib., “¡Oh humildad, humildad! No sé qué tentación me tengo en este caso, que no puedo acabar de creer a quien tanto caso hace de estas sequedades, sino que es un poco de falta de ella. Digo que dejo los trabajos grandes interiores que he dicho, que aquellos son mucho más que falta de devoción. Probémonos a nosotras mismas, hermanas mías, o pruébenos el Señor que lo sabe bien hacer, aunque muchas veces no queremos entenderlo".

(124) Ib., "vengamos a estas almas tan concertadas, veamos qué hacen por Dios y luego veremos cómo no tenemos razón de quejarnos de su Majestad, porque si le volvemos las espaldas y nos vamos tristes como el mancebo del Evangelio (Mt 19, 22) cuando nos dice lo que hemos de hacer para ser perfectos ¿qué queréis que haga su Majestad que ha de dar el premio conforme al amor que le tenemos? Y este amor, hijas, no ha de ser fabricado en nuestra imaginación, sino probado por obras; y no penséis que ha menester nuestras obras, sino la determinación de nuestra voluntad". 
Se detectan, al menos, dos dilemas: humildad o soberbia; y vigilancia o descuido. Respecto al primero, el hombre engreído reclama y se queja de todo lo que le sucede, cualquier problema le desborda e impide la asunción del sufrimiento real, inventa lo que sea y de ese modo no crece en la humildad; cree que no se merece lo que le pasa, o incluso culpa a otros o al mismo Dios. Por otro lado, el ser humano no puede "volver las espaldas", sino que desde la vigilancia permanente, vela por el seguimiento que es amor fecundo.

Es responsabilidad humana el desarrollo pleno del hombre. El Señor ya ha revelado el camino de perfección, el proyecto de seguimiento (Mt 19, 22) y es tarea de la libertad humana seguirlo. El proyecto propuesto al joven rico es la vida con determinación conforme al amor. Dios es gratuito y el hombre, creado a su imagen y semejanza, no se esfuerza por el premio sino porque así se realiza como auténtico hombre en el mundo.

Se aborda el proceso evolutivo de la persona a través de la purificación. En esta etapa de la vida (30-40) se invita al seguimiento sin entretención. El camino consiste en que la razón ceda terreno al amor. En este texto se ironiza la ecuanimidad de las personas con cierto recorrido, y anima a la rapidez en el camino difícil. "No está aun el amor para sacar de razón" (125).

La cordura y prudencia de personas ordenadas y ajustadas se expresa en elementos adecuados para el crecimiento: la valoración de la vida; el cuidado de la salud; la prudencia en cualquier acción acometida, incluso en la penitencia (126). Sin embargo, se ironiza (127) y denuncia la diferente medida: es razonable y prudente para el cuidado de sí, pero no es tan cuerda para el servicio de Dios (128). La razón domina el amor (129): controla al ser humano, le hace juicioso y responsable. Este tipo de vida se supera cuando el amor crece (130).

El proceso de crecimiento y purificación es costoso, por lo cual es imprescindible el cuidado y la atención que evite el desvío y la pérdida, aunque el cansancio pretenda ralentizar la marcha (131). Por las dificultades es preferible recorrerlo pronto, rápido, sin demora y sin rodeos: se busca lo adecuado sin enredos en los vericuetos presentados a lo largo de la existencia. Invita a la audacia, los riesgos en momentos aumentan, pero no hay que temerlos sino andar ligero el camino, evitando el tedio y el hastío innecesarios (132). Desde la experiencia personal de superación

(125) Cf. 3M 2, 7.

(126) Ib., "Las penitencias que hacen estas almas son tan concertadas como su vida; quiérenla mucho para servir a nuestro Señor con ella; que todo esto no es malo, y así tienen gran discreción en hacerlas, porque no dañen a la salud".

(127) Ib., "No hayáis miedo que se maten".

(128) Ib., "mas querría yo que la tuviésemos para no nos contentar con esta manera de servir a Dios, siempre a un paso que nunca acabaremos de andar este camino".

(129) Ib., "porque su razón está muy en sî".

(130) Ib., "no está aún el amor para sacar de razón".

(131) Ib., "Y como, a nuestro parecer, siempre andamos y nos cansamos, porque -creed que es un camino brumador- harto bien será que no nos perdamos".

(132) Ib., "Mas ¿paréceos, hijas, si, yendo a una tierra, desde otra pudiésemos llegar en ocho días, que sería bueno andarlo en un año por ventas y nieves y aguas y malos caminos? ¿No valdría más pasarlo de una vez? Porque todo esto hay, y peligros de serpientes". 
de esta etapa, aunque a veces dude de ello, Teresa se presenta como signo e instrumento de Dios (133).

El dilema entre razón o amor se resuelve en progresiva armonización. La razón conduce a la constancia de ánimo y la prudencia respecto al cuidado de sí; y el amor provoca que se aplique también al servicio del Reino. Esta resolución del dilema se logra en un proceso de purificación: donde el amor gana terreno a la razón (134).

En síntesis, la compenetración de amor y razón se va configurando progresivamente. La primacía de la razón, paso adecuado para la comprensión del mundo, ayuda a la asunción de la realidad abriendo(se) a otra dimensión que la supera, y tira más allá de las propias posibilidades de la razón. La limitación de la realidad, la vanidad devorada por gusanos, puede abrirse a los signos de amor y, sobre todo, acoger al dador de la vida y la existencia (Cf $2 \mathrm{M} \mathrm{1,4).} \mathrm{El} \mathrm{seguimiento} \mathrm{de} \mathrm{Jesús,} \mathrm{más}$ allá de lo que fue el joven rico, desde la humildad y el sufrimiento por la realidad,

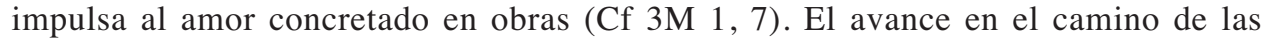
moradas conduce al desbordamiento de la razón en el amor, a través del conocimiento de sí (Cf 3M 2,7).

\subsection{Relación equivalente entre amor y razón}

Después del estudio de la primacía de la razón, desde la perspectiva de la realidad del mundo, se da el paso hacia una igualdad entre amor y razón en el contexto de la relación con los otros. En este apartado se plantea la posibilidad de la razón de transcender y abrirse al amor. La razón atisba el valor del agradecimiento y llega al amor. Para ello se requiere un proceso de conocimiento, los otros tiene su papel en esta tarea: en la relación con los otros se va dando la equivalencia entre amor y razón.

En continuidad con lo dicho anteriormente (135), la razón realiza su apertura al amor de tres posibles maneras (136). El exceso de precaución viene provocado por el temor, que impide el camino y cae en la inconsistencia del deseo de la meta sin el recorrido del camino (137).

Ante la precaución se propone la audacia, que consiste en extremar la confianza. El incremento en seguridad requiere el abandono del temor; restar valor a la limitación; y caminar con presura. El miedo se pierde con una apuesta mayor: en vez de la medida y el control, se entrega la razón en el amor del Señor (138). No es posible la pretensión de alcanzar el objetivo, sin los medios adecuados; se requiere un serio trabajo para que la razón no juegue en contra, para que los miedos no

(133) Ib., “¡Oh!, ¡qué buenas señas podré yo dar de esto!; y, ¡plega a Dios!, que haya pasado de aquí; que hartas veces me parece que no".

(134) Ib., "No hayáis miedo que se maten, porque su razón está muy en sí; no está aún el amor para sacar de razón; mas querría yo que la tuviésemos para no nos contentar con esta manera de servir a Dios, siempre a un paso que nunca acabaremos de andar este camino".

(135) Cf. 3M 2, 7.

(136) Cf. 3M 2,8.

(137) Ib., "Como vamos con tanto seso todo nos ofende: porque todo lo tememos y así no osamos pasar adelante, como si pudiésemos nosotras llegar a estas moradas y que otros anduviesen el camino".

(138) Ib., "Pues no es esto posible, esforcémonos, hermanas mías, por amor del Señor; dejemos nuestra razón y temores en sus manos". 
encorseten ni paralicen. La confianza se teje sin la absolutización de la propia debilidad (139). La autorrealización, el cuidado de sí, el culto al cuerpo, no han de convertirse en grandes obstáculos para el camino hacia la plenitud humana.

La osadía de la seguridad pasa por el camino rápido, ligero, sin detención en pequeñeces. Se camina al encuentro del Señor, hay una cierta prisa escatológica, el premio es el encuentro definitivo; es el mejor regalo en la vida de servicio (140). Por eso se recomienda la vigilancia ante el engaño de la salud, que centra en sí mismo y encorva: a mayor preocupación y excesivos cuidados no le corresponde ni más mejoría, ni ausencia de enfermedad. Desde la experiencia de dolencias continua, habla con propiedad para que se avance con la propia incapacidad corporal (141).

La tercera manera como la razón se abre al amor es procurando la humildad, esta es la virtud fundamental para la reforma. La carencia de ella retrasa el conocimiento, y la razón no deja espacio al amor (142). La consideración de los demás como superiores a uno mismo (Flp 2, 3), lleva a la alegría por el progreso de los otros sin envidia (143). Desde un humilde concepto de sí crece la capacidad para el amor y el servicio; desde el anonadamiento las limitaciones, propias y ajenas, se convierten en causa de acercamiento y comunión. No se trata de competencia, ni de una condena al éxito, por eso la razón no es la diosa, sino que el amor es el enlace de las relaciones.

Los dilemas razón o amor; temor o confianza encuentran respuesta. La razón se puede enredar en el temor, en el excesivo cuidado de sí; y el amor orienta hacia la confianza y a caminar ligeros desde la humildad. La razón se abre al amor gracias a la audacia de confiar, venciendo el temor, relativizando la propia limitación y fomentando la pequeñez.

La razón atisba el agradecimiento y alcanza el amor (144). El descubrimiento de lo valioso que es el ser humano para Dios, engendra gratitud. El contenido central del texto es el sentido y significado de la reflexión sobre la acción de Dios (145).

Teresa acomete la tarea de escritora para que otros entiendan que son agradables a Dios y nazca en ellos la gratitud y la alabanza; no es otra la pretensión (146).

(139) Ib., "olvidemos esta flaqueza natural, que nos puede ocupar mucho; el cuidado de estos cuerpos ténganle los prelados; allá se avengan".

(140) Ib., "nosotras, de solo caminar aprisa para ver este Señor; que, aunque el regalo que tenéis es poco o ninguno".

(141) Ib., "el cuidado de la salud nos podría engañar, cuánto más que no se tendrá más por esto, yo lo sé, y también sé que no está el negocio en lo que toca al cuerpo, que esto es lo menos".

(142) Ib., "que el caminar que digo es con una grande humildad, que, si habéis entendido, aquí creo está el daño de las que no van adelante".

(143) Ib., "sino que nos parezca que hemos andado pocos pasos y lo creamos así, y los que andan nuestras hermanas nos parezcan muy presurosos y no solo deseemos sino que procuremos nos tengan por la más ruin de todas".

(144) Cf. 3M 2, 11.

(145) Ib., "mercedes interiores". Cf 3M 2, 10. Empieza a formular el significado y la diferencia entre gusto y contento, y añade que lo va a desarrollar más en las cuartas Moradas.

(146) Cf., 3M 2, 11: "Pareceros ha que ¿de qué sirve tratar de estas mercedes interiores y dar a entender cómo son... Yo no lo sé; pregúntese a quien me lo manda escribir; que yo no soy obligada a disputar con los superiores, sino a obedecer, ni sería bien hecho". El sentido de comunicar la experiencia de Dios y la utilidad de ello hay que buscarlo en quien lo ha mandado escribir. Si no sirvieran para nada, sus escritos, al menos cumple con la obediencia. No quiere polémica con los superiores, no desea competir con nadie. Hábil manera de abrirse camino para comunicar su experiencia de Dios, decir lo que piensa, y no provocar la rivalidad de los superiores. 
Únicamente comunica la experiencia de la gracia para que redunde en agradecimiento al donante que se complace en su creatura. Al menos desde este punto de vista, la finalidad o la utilidad de sus escritos queda relativizada (147).

La gracia de Dios actúa en todo hombre (148) y reitera la conveniencia de comunicar dicha experiencia para que se fomente la alabanza, y descubra la pérdida que supone el silencio de la presencia de Dios en el hombre. Por el contrario atreverse a expresar la presencia de Dios provoca que otros gocen de su amor y de sus dones. Esta experiencia de la gracia estimula el proceso de conversión al amor, y encamina hacia la plenitud de una vida entregada (149).

La gratuidad de Dios que comunica sus dones, y la acogida esforzada (150) por parte del sujeto, pertenece al misterio (151) de la relación humano-divina. Sin embargo, existe la certeza de que se recibe lo conveniente (152). La justicia de Dios se expresa en varios salmos, que destacan el poder de Dios en ala harmonización de los deseos con la realidad (Sal 118; 137; 17; 15; 144).

Se descubren dos dilemas: obedecer o disputar, y, eficacia o gratuidad. Al comunicar la experiencia de Dios se dice lo que se piensa, y además se obedece a los superiores (153). Por otro lado, está la contraposición entre la eficacia de la comunicación de la interioridad, frente a la gratuidad de la experiencia (154). El dilema se hace comunión, se conjunta: la gracia de Dios, el deseo de comunicar el gozo desbordante y la necesidad de obedecer a los superiores. La eficacia de la gracia no se mide por la cantidad, aunque únicamente ayude a una persona ya es válido el esfuerzo. Cada cual realiza su tarea, su esfuerzo y, sin duda, Dios dará lo que le conviene.

La resolución del dilema del sentido, la eficacia y la utilidad de la acción de Dios, viene dada por el descubrimiento de que el hombre alberga lo que Dios otorga sabiamente, aunque no se comprenda. Desde ese descubrimiento personal e intransferible, el hombre se sabe impulsado al amor, a transcenderse, yendo más allá; y esto necesita comunicarlo.

(147) Ib., "Lo que os puedo decir con verdad es que, cuando yo no tenía ni aún sabía por experiencia ni pensaba saberlo en mi vida -y con razón, que harto contento fuera para mí saber o por conjeturas entender que agradaba a Dios en algo- cuando leía en los libros de estas mercedes y consuelos que hace el Señor a las almas que le sirven me le daba grandísimo, y era motivo para que mi alma diese grandes alabanzas a Dios".

(148) Ib., "Pues si la mía, con ser tan ruin, hacía esto, las que son buenas y humildes le alabarán mucho más;".

(149) Ib., "y por sola una que le alabe una vez es muy bien que se diga, a mi parecer, y que entendamos el contento y deleites que perdemos por nuestra culpa si son de Dios vienen cargados de amor y fortaleza con que se puede caminar más sin trabajo e ir creciendo en las obras y virtudes".

(150) Ib., "No penséis que importa poco que no quede por nosotros".

(151) Ib., "su Majestad sabe, que son muy ocultos sus secretos; al menos será lo que más nos conviene, sin duda ninguna".

(152) Ib., "cuando no es nuestra la falta, justo es el Señor y su Majestad os dará por otros caminos lo que os quita por este".

(153) Ib., "¿de qué sirve /.../ pregúntese a quien me lo manda escribir; que yo no soy obligada a disputar con los superiores, sino a obedecer, ni sería bien hecho".

(154) Ib., “¿de qué sirve tratar de estas mercedes interiores y dar a entender cómo son /.../ Lo que os puedo decir con verdad es /.../ era motivo para que mi alma diese grandes alabanzas a Dios". Teresa cuando solo tenía noticias por sus lecturas de la gracia de Dios, ya estaba contenta; pero después, cuando lo experimenta, se desborda de gozo y eso mismo la lanza a comunicar esa experiencia de Dios. La obediencia es hacer caso a lo que escucha y transmitirlo. 


\subsection{Supremacía del amor}

En los dos apartados anteriores se ha tratado la primacía de la razón, en la perspectiva de la realidad del mundo; y la igualdad entre amor y razón en el contexto de la relación con los otros. En este momento se vislumbran algunos aspectos de superioridad del amor (155). La primacía del amor desencadena un acercamiento a Dios (4M 2, 8-9) que dilata el corazón (4M 1, 5). En las cuartas moradas se afirma que la razón desea y procura el amor porque plenifica al ser humano.

La razón desea el conocimiento del amor que acerca a Dios y procura esa experiencia (156). A través de la contemplación se perciben atisbos de plenitud en este mundo y a través de la acción humana se muestra la unión con Dios. Es un gran don de Dios que la persona conozca la gracia que recibe, la presencia de Dios en él, y desee el proceso. La razón apetece la experiencia de oración para el descubrimiento de la profundidad humana. El hombre anhela el camino hacia el amor, porque aspira al gozo, acá en la tierra, de lo definitivo. El dilema entre el mejoramiento o la regresión, no se inclina al retroceso sino al avance en el camino progresivo del conocimiento hacia el amor. El ser humano conociéndose ensancha su ser, y el amor brota en él como manantial.

La razón descubre que el amor plenifica al hombre (157). Se presenta una imagen de Dios libre, a quien no se obliga a la acción; Dios sabio, conoce lo que conviene y sabe quien le ama; y Dios gratuito que colma al ser humano, sin que este se canse. La razón consiente que Dios actúe y que el hombre cultive la humildad. Sin merecerlo ni buscarlo se recibe la gracia. La única pretensión es el seguimiento de Jesús; imitando y padeciendo su vida, muerte y resurrección, todo lo demás se espera por añadidura. La libertad divina enseña que esta experiencia solo Él la concede, por ello no hay que cansarse, pues no viene por artilugios sino simplemente es manantial que brota inmerecidamente. El dilema se presenta en relación con la actitud tomada en este proceso de conocimiento: se opta por el empeño y esfuerzo o por la humildad y el inmerecimiento. Ante esta disyuntiva se descubre la gratuidad y, desde la humildad, la razón acoge la libertad de Dios actuando en el hombre que ama desde el seguimiento de Cristo.

Nuevamente, y como colofón de esta segunda parte del estudio, la transformación del dilema, Teresa trata de dar a entender la diferencia entre contento y gusto, el salmo 118, 32 lo expresa de modo espectacular. Se señala cómo el conocimiento capacita para la acogida del amor (158). "Tú dilataste mi corazón”, refleja la experiencia de contento que progresivamente va teniendo atisbos de gusto. El corazón, sede del amor, se ensancha gracias al mayor conocimiento de sí mismo, de los otros y de Dios. Los contentos comprimen un poco, porque son movidos por el interés, el prestigio, el poder y la vanagloria. La autora se lamenta de la incapacidad para

(155) Teresa, lógicamente, lo aborda en las cuartas Moradas, donde acontece el quiebre de etapa hacia la mística. Por eso solo se deja indicado, como tarea para una próxima investigación.

(156) Cf. 4M 2, 8 .

(157) Cf. 4M 2, 9.

(158) Cf. 4M 1, 5. 
expresar la experiencia; enfatiza su gran pasión por la cultura (159). Ahora, en concreto, añora conocimiento referido a la psicología, a la profundidad humana y sus mecanismos (160), para una adecuada comunicación de su vivencia.

En el contento falta aun conocimiento para alcanzar el gusto. La comprensión del misterio del hombre y de Dios conduce de la razón al amor; la sabiduría ensancha la capacidad humana que se llena de amor. El Señor abre, insufla con su aliento el corazón de barro humano para el amor comprendiendo los dilemas.

\section{EL DILEMA SE SUPERA}

El gran dilema humano se supera en la transcendencia, de una manera asombrosa, gracias al Espíritu Santo.

\section{La salvación resuelve el dilema}

La resolución del dilema existencial humano se produce de manera asombrosa en la dinámica de la salvación. El sentido último de la existencia tiene una manera de llevarse a cabo, y produce pasmo y asombro en quien alcanza a conocerlo.

El descubrimiento del poder del mal, conduce a un proceso inicial de conversión (4.1). La salvación se va experimentando con progresividad; tras la inicial conversión, luego aparecen (4.2) pruebas (a) que ayudan al autoconocimiento (b). Tras la conversión y la purificación se llega a la plenificación como cumplimiento (4.3).

\subsection{La conversión: inicial descubrimiento del sujeto y su entorno}

La conversión se inicia desde una toma de conciencia, que requiere conocimiento y discernimiento $(1 \mathrm{M} 2,11)$, de la realidad de miseria y pecado a todo nivel $(1 \mathrm{M} \mathrm{2,5).} \mathrm{Solo} \mathrm{desde} \mathrm{la} \mathrm{conciencia} \mathrm{de} \mathrm{pecado} \mathrm{se} \mathrm{apuesta} \mathrm{por} \mathrm{la} \mathrm{conversión.}$

El pecado mortal conduce a la experiencia del poder del mal (161). Se necesita lucidez y la ayuda de Dios, para el no ingreso en el círculo permanente del mal, es decir, que el pecado mortal no envuelva. El espanto se produce por la omisión, es decir, por lo que no se hace. La petición para una vida ajena a la vanidad compromete la construcción de la propia existencia y el reconocimiento del cuidado por parte de Dios (162).

(159) Ib., “'Gran cosa es el saber y las letras para todo!”.

(160) Ib., "Yo sé poco de estas pasiones del alma, /.../, y lo que procede de la sensualidad y de nuestro natural, ...".

(161) 1M 2, 5: "Oí una vez a un hombre espiritual que no se espantaba de cosas que hiciese uno que está en pecado mortal, sino de lo que no hacía".

(162) Ib., “Dios por su misericordia nos libre de tan gran mal, no hay cosa mientras vivimos que merezca este nombre de mal sino esta, pues acarrea males eternos para sin fin! Esto es, hijas, de lo que hemos de andar temerosas y lo que hemos de pedir a Dios en nuestras oraciones, porque si él no guarda la ciudad en vano trabajaremos, pues somos la misma vanidad". 
La clarividencia humana (163) descubre: el poder del mal y la debilidad humana, que no puede nada sin la ayuda de Dios (164). El reconocimiento de la condición humana posibilita el ascenso en humildad (165). Se admite la debilidad aceptando la existencia como dependiente absolutamente del exterior, viene de fuera de sí misma, no se la puede dar uno a sí mismo (166). De este modo, se inicia la apertura a la recepción de ayuda, consciente de la propia incapacidad para tal empresa (167). La limitación asumida, se expresa en la humildad y conduce a la alabanza de quien lo sostiene (168). El espanto se produce cuando el mal invade la existencia; esa experiencia provoca que el hombre lúcido pida no caer en pecado y eso da origen al respeto por la obra de Dios en cada hombre que no peca.

El dilema se formula entre el mal que se hace o el mal que no se hace. El ser humano no se pasma de lo primero, sin embargo, le asombra lo que no hacía (1M 2 , 5). La persona que se sitúa en camino de conversión inicial va tomando conciencia de la debilidad humana y evita el pecado.

El conocimiento personal es el punto de partida para la conversión. La tarea consiste en el descubrimiento de la finitud, por un lado, y el mirar a Cristo, por otro (169).

La persona se pierde, no llega a la plenitud, al encerrarse en sí misma (170). El ensimismamiento, tratado en puntos anteriores, significa una vida en pecado mortal (171). La razón se complica, se oscurece, se encorva generando el desconocimiento personal y una mala comprensión de los valores fundamentales (172). Teresa no se espanta del temor que produce el encorvamiento (173), y fijando la mirada en Cristo invita a una vida de anonadamiento (174) que manifiesta el camino para un conocimiento elevado y audaz (175), que permite la continuación en las moradas sin contentarse con la finitud.

Los primeros pasos en la vida interior son valiosos y costosos: la decisión para el inicio del camino vocacional es una gran apuesta, un salto en el vacío; y a la vez, es

(163) Ib., "había sacado dos cosas de la merced que Dios le hizo /.../ se le representó esto tan claro".

(164) Ib., "un temor grandísimo de ofenderle y así siempre le andaba suplicando no la dejase caer viendo tan terribles daños".

(165) Ib., "un espejo para la humildad /.../ no se acordaba de sí en cosa buena que hiciese".

(166) Ib., "no viene su principio de nosotros, sino de esta fuente adonde está plantado este árbol de nuestras almas, y de este sol que da calor a nuestras obras".

(167) Ib., "cosa buena que hagamos no viene su principio de nosotros /.../ haciendo alguna cosa buena o viéndola hacer, acudía a su principio y entendía cómo sin esta ayuda no podíamos nada".

(168) Ib., "sin esta ayuda no podíamos nada; y de aquí le procedía ir luego a alabar a Dios".

(169) Cf. 1M 2, 11.

(170) Ib., "¡Oh, válgame Dios, hijas, qué de almas debe el demonio de haber hecho perder mucho por aquí!".

(171) Cf. 1M 2 10: "nunca salimos de nuestro cieno de miserias" "están en pecado mortal" "metidos siempre en la miseria de nuestra tierra".

(172) Cf. 1M 2, 11: "que todo esto les parece humildad y otras muchas cosas que pudiera decir, y viene de no acabar de entendernos; tuerce el propio conocimiento y, si nunca salimos de nosotros mismos".

(173) Ib., "no me espanto que esto y más se puede temer".

(174) Ib., "pongamos los ojos en Cristo nuestro bien, y allí deprenderemos la verdadera humildad".

(175) Ib., "y ennoblecerse ha el entendimiento, como he dicho, y no hará el propio conocimiento ratero y cobarde". 
un tiempo denso e intenso (176). El único requerimiento es el abandono de lo mundano para avanzar en el proceso del conocimiento (177). La persona, hábilmente, se aparta de lo perjudicial, de toda realidad que encierra y acorta la mirada. Aunque la persona desea el proceso, las astucias y sagacidades, los artificios y habilidades de la realidad mundana ponen impedimentos, por todos los medios a su alcance, para el conocimiento y el avance del sujeto (178). El mundo, en sentido joánico, atrae hacia sí y el hombre se fascina de sus encantos, es decir, se encorva y no se transciende.

El conocimiento llega al descubrimiento de la realidad, la sitúa y decide el desapego del mundo; y, al mismo tiempo, apuesta por la propuesta de Cristo que da altura y audacia a la pretensión humana más noble. La tarea de esta etapa existencial es la negación del pecado y la afirmación de Cristo. La primera conversión es fundamental en la vida porque decide el curso de la existencia, e influye en todo el resto de la vida. Se apuesta por algo mayor o la persona se limita a lo mundano.

Algunas expresiones que aterrizan el gran dilema humano son: encorvarse altivamente o enderezarse humildemente; desconocimiento o conocimiento; apego al mundo o modesta renuncia; estancamiento o progreso en las moradas. El conocimiento oscurecido encierra, encorvando sobre sí mismo; en cambio Cristo muestra el abajamiento como el auténtico conocimiento de sí. La astucia centra en uno mismo, y la humildad abre a la transcendencia. El miedo a conocerse es razonable debido al poder del mal. Desde las primeras moradas, se presenta al ser humano como valioso, y el autoconocimiento, poniendo la mirada en Cristo, en la transcendencia, es el comienzo del buen camino.

A modo de síntesis, el dilema se supera descubriendo la realidad del entorno. La lucidez que detecta el mal, junto a la claridad de razonamiento para que el ser humano no se acomode a la mediocridad, capacita para configurarse con Cristo humilde. El dilema se supera descubriendo la realidad del sujeto que necesita conocerse y optando por los valores que llevan a la plenitud. La salida del encorvamiento, que enturbia el entendimiento y nubla la razón, para pensar de modo audaz y elevado. El abandono de lo mundano, con esfuerzo continuo, es necesario para encaminarse hacia lo profundo.

\subsection{La prueba: progresivo conocimiento desde la relacionalidad}

La salvación se va experimentando de manera progresiva. Tras la inicial conversión, también obra de la gracia de Dios, las pruebas aparecen y ayudan al autoconocimiento. El dilema se supera a través del conocimiento que aporta la relación con

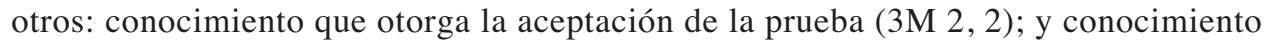
adquirido a raíz de la limitación de los otros $(3 \mathrm{M} 2,13)$.

La persona con cierto recorrido personal y creyente, al inicio del proceso de purificación intenta conocerse, aceptar la prueba y superar la imperfección (179). El

(176) Ib., "que, aunque esta es la primera morada, es muy rica y de tan gran precio".

(177) Ib., "descabulle de las sabandijas de ella, no se quedará sin pasar adelante".

(178) Ib., "son los ardides y mañas del demonio para que las almas no se conozcan ni entiendan sus caminos".

(179) Cf. 3M 2, 2. 
conocimiento descubre, junto con las grandezas, las miserias y limitaciones humanas. En la condición existencial de las terceras moradas, se hace un recorrido perseverante y con un plan estable de vida. En ese tiempo, la dificultad conduce al engaño; no es fácil la aceptación de las miserias y con facilidad se cae en la soberbia. Pero, también, las limitaciones asumidas, e incluso superadas encaminan hacia la configuración con la voluntad de Dios.

La prueba que patentiza la propia verdad, se presenta como inquietud, apretamiento de corazón, sequedad (180), y en este texto, como dolor por las faltas y por la afinidad al mundo (181). En esta etapa se propone la aceptación de la realidad, pobre, limitada, sin engaños, porque es una oportunidad para la humildad, para el reconocimiento de la imperfección y para sentir la ausencia de Dios. Esta situación de prueba ocasiona ganancia.

Es urgente el conocimiento personal, profundizando sin espantarse. El viaje al interior de sí, no conviene dilatarlo ni posponerlo, sino acompasarlo como un proceso a lo largo de toda la vida que desenmascara el engaño y la justificación (182). La manera es apresurarse en el afrontamiento de las propias debilidades para que sean provechosas. La prueba ayuda al conocimiento (183); hay que pasarla con prontitud y brevedad (184); todo de modo diligente, preparado y dispuesto (185).

Se presenta el siguiente dilema: la prueba ¿es engaño o es favor de Dios? La prueba, presentada como sequedad, apretamiento, dolor y excesiva vinculación al mundo, desvela el posible autoengaño y ayuda a la evolución. Otro dilema se refiere al dolor por la propia miseria ¿es falta o es ganancia? Mientras se da este periodo de juicio, hay desconcierto, se experimenta pena, desasosiego; todo ello conduce al encorvamiento sobre sí mismo; se vive en la noche y en la oscuridad. Al mismo tiempo, si el ser humano reconoce, acepta y asume la condición de limitación y de apego a lo mundano; la misma realidad se convierte en medio para el conocimiento y la persona sale fortalecida. En ese sentido es ganancia.

En síntesis, el conocimiento consiste en la apuesta por la debilidad y la pobreza de lo humano, la limitación del mundo y la experiencia de desarrollo en un determinado contexto.

La imperfección de los otros ayuda en el proceso de conocimiento (186), porque la relación y las dificultades surgidas son ocasión para la superación del dilema.

Las personas con recorrido humano y cristiano prioritariamente han de centrarse en los propios errores (187); pero también necesitan el aprendizaje de las faltas ajenas (188). Los otros, aunque en las formas no sean expertos (189), de-

(180) Cf. 3M 2, 1.

(181) Cf. 3M 2, 2: "porque entienden ellos su falta muy claramente y, a las veces, les da más pena esta de ver que, sin poder más, sienten cosas de la tierra y no muy pesadas".

(182) Ib., "todas las conciertan en su pensamiento que por Dios las sienten".

(183) Ib., "sientan su miseria y aparta un poco su favor".

(184) Ib., "pasar presto".

(185) Ib., "bien presto".

(186) Cf. 3M 2, 13.

(187) Ib., "Miremos nuestras faltas y dejemos las ajenas, que es mucho de personas tan concertadas espantarse de todo".

(188) Ib., "de quien nos espantamos podríamos bien deprender en lo principal,".

(189) Ib., "y en la compostura exterior y en su manera de trato le hacemos ventajas". 
nuncian muchas actitudes de engreimiento. Si se reconoce la propia ignorancia y se apuesta por la libertad y la pluralidad, la persona vive abierta y en proceso (190). Un apropiado conocimiento de sí cuestiona ciertos ímpetus (191) y afanes desmedidos que obstaculizan el proceso de los demás. Esto se evita al centrarse en lo fundamental (192): cada uno viva pendiente de su propio proceso de conocimiento desde la llamada recibida; la fidelidad en lo pequeño, sin discursos ni aspavientos y con confianza en las propias capacidades con sus límites (193). La ausencia de pretensión para que los otros se conviertan al propio proyecto revela que los caminos del Señor son insondables, y, además, Él cuida admirablemente de sus criaturas (194). La persona vigilante pide que el Señor cuide de su obra, y con su ayuda se empeña en la construcción del Reino, sin camuflarlo en las propias pretensiones (195).

Ante el dilema de lo propio o lo ajeno, se decide por la confesión de la propia limitación y aprende de los otros; desde el conocimiento humilde y silencioso se es testigo y enseña. En el contraste entre la uniformidad o la pluralidad, se apuesta por la fidelidad y radicalidad de cada uno a la comunión. De este modo, se supera el afán de dominio, incluso por una buena causa como es la conversión de los demás. Ante la confianza o la desconfianza se llega a que Dios cuida de su obra, y el hombre, siervo inútil, hace lo que debe.

En síntesis, la persona en camino, con cierto recorrido existencial, no critica lo ajeno ni pretende que todos vayan por el propio camino. Si no que se proponen algunos retos: la imperfección ajena instruye; el respeto de la pluralidad y el reconocimiento de las propias limitaciones; una vida centrada en la conformidad con la vocación recibida; la petición confiada porque el Señor cuida su obra. Dios es el primer interesado en la realización de su proyecto para que toda la humanidad alcance la plenitud, contando con la cooperación del hombre. Dios tiene caminos nuevos y distintos para cada persona, aunque el hombre no lo entienda. La libertad de Dios posibilita al ser humano una existencia preocupada, únicamente, por servir al proyecto del Reino.

El pasmo y asombro surgen porque se admira y se descubre en los otros cosas valiosas. No será nunca grande la insistencia en el propio conocimiento y el aprendizaje, incluso, desde las faltas ajenas, sin espantarse. Para ello se requiere la humildad, la sencillez, el silencio, sin pretensiones de que otros sigan el propio camino.

(190) Ib., “y no es esto lo de más importancia, aunque es bueno, ni hay para qué querer luego que todos vayan por nuestro camino,". "ni ponerse a enseñar el del espíritu quien por ventura no sabe qué cosa es"

(191) Ib., "que con estos deseos que nos da Dios, hermanas, del bien de las almas, podemos hacer muchos yerros".

(192) Ib., "y así es mejor llegarnos a lo que dice nuestra Regla".

(193) Ib., "en silencio y esperanza procurar vivir siempre".

(194) Ib., "que el Señor tendrá cuidado de sus almas".

(195) Ib., "como no nos descuidemos nosotras en suplicarlo a su Majestad, haremos harto provecho con su favor. ¡Sea por siempre bendito!”. 


\subsection{El cumplimiento: plenificación del pensar en el amar}

Tras la conversión y la purificación se llega a la plenificación que sería la meta final de la salvación. Se ha dicho que solo desde la conciencia de pecado se apuesta por la conversión; también, la salvación se vive desde las pruebas purificadoras. Ahora se aborda el proceso de cumplimiento: hacia dentro, la oración y la interioridad; y hacia fuera, la acción y el compromiso.

El tema estudiado, El dilema de la razón, se sitúa en el ámbito del conocimiento (196) humano, y siendo un proceso permanente para toda la vida, se detecta más desarrollado en las tres primeras moradas. A partir de la cuarta morada se da el paso del pensar al amar $(4 \mathrm{M} 1,7)$, y por eso se presenta con más detenimiento el ámbito del amor.

En el capítulo segundo de las cuartas moradas, Teresa aborda la profundidad del hombre que acoge y guarda la grandeza de Dios (197). El corazón se ensancha (Salmo 118, 32) hacia lo profundo, hace hueco para la acogida (198). El develamiento de la hondura humana acerca a la grandeza de Dios y a los secretos del hombre, que habitan en el centro del alma. En el hombre nace el espanto al darse cuenta de los misterios ("secretos") que encierra en sí y de la posibilidad de alcanzarlos: así se supera el dilema en la transcendencia. La grandeza humana es producida por la perfecta unidad del hombre, en la que todas sus potencias (199), no solo están unidas, sino embebidas.

El dilema entre pequeñez o grandeza se resuelve así: la grandeza de Dios se refleja en lo profundo de la creatura. Dios ensancha el interior del hombre y así se expresa mejor el gran misterio del ser humano.

En 4M 2, 6 se sigue explicando la presencia de Dios a través de imágenes que expresan lo que sucede en la interioridad del hombre. Lo profundo del ser

(196) Cf. Körner, R., "El papel de la razón en la mística...”, 200. A modo de síntesis: 1. La mística hace que la potencia cognoscitiva humana se supere a sí misma, participe de la "ratio aeterna". 2. La visión místico-contemplativa es el acto supremo de la percepción intelectual. 3. Para la visión intelectual de la realidad mística tiene que callar la razón, prescindir de la actividad discursiva del espíritu para darse cuenta de la unión. 4. Se conserva el saber elevándolo en un triple sentido dialéctico: relativizarlo, conservarlo, y elevarlo adentrándolo en lo experimentado místicamente. 5. La razón hace que la mística pueda convertirse en mística cristológica y trinitaria. El "NoSaber" místico en relación con el Saber que otorga la revelación y la teología natural, por la razón, puede ser interpretado y situado. 6. La razón puede beber de la mística, relaciona lo divino con los conocimientos adquiridos. La experiencia y el conocimiento místico constituyen una nueva premisa, una nueva perspectiva, para todo buscar, juzgar y deducir discursivo de la actividad racional del espíritu.

(197) Cf. 4M 2, 5.

(198) Volverá sobre la misma imagen de la dilatación que ensancha en las séptimas moradas, capítulos uno y dos.

(199) Cf. Ofilada Mina, M., "Según su condición y propiedades". O la gracia presupone la naturaleza: el hombre, experiencia de Dios en San Juan de la Cruz, Carmelus 47 (2000) fasc. 1, 73-90. Un pequeño aporte: a. El hombre puede tener experiencia de Dios, el hombre como "estar ahí", como "facticidad" y como ser arrojado"; y como "constitucionalidad". b. El hombre en su hondura se debate entre replegarse o abrirse; entre ser despojo de sí o entrega de sí. c. El fundamento de lo humano en Santa Teresa lo estudio a través de dos palabras: encorvarse y entregarse. La hipótesis que se está investigando se va resolviendo: la razón o se contenta con su finitud o se transciende al infinito en el Espíritu Santo por el amor. 
humano se dilata, se ensancha para la aceptación de lo que brota de sí mismo, del fondo de la persona. La imagen que usa expresa la real experiencia que penetra todo el ser. Es de una delicadeza tal que no se inventa ni se consigue con el esfuerzo humano; es puro don gratuito de la "sabiduría divina": es agua y fuego; es brasero de perfumes olorosos; "ni se siente calor... ni se huele"; es la experiencia delicada de lo inefable.

El dilema se supera desde la sabiduría divina que inunda la ignorancia humana sobre el amor, de manera delicada. Se experimenta la unidad en lo profundo de sí y la capacidad de recepción de lo divino; es la apertura a la transcendencia. El ser humano se asombra y sobrecoge ante la presencia de Dios en su interior que le dilata y ensancha hasta desbordarse.

Llegando al final de este apartado se afirma: "No está la cosa en pensar mucho sino en amar mucho" (200). En todo el proceso de conocimiento, se van resolviendo diversos dilemas que son concreciones del gran dilema humano. En este momento se alcanza la superación del dilema. El amor consiste en la determinación y el empeño por el anuncio del Evangelio y la cooperación en la construcción de la Iglesia, el amor es la razón fundamental para una vida profunda y con sentido en esta nueva etapa existencial, mística o sobrenatural. Esto no se comprende con facilidad, por eso Teresa habla de no espanto cuando no se sabe amar. El amor es lo fundamental porque plenifica al hombre (201).

El dilema se supera en la plenificación del pensar en el amar, entre ambos se da una compenetración: cuando el ser humano reconoce que no sabe amar se da la posibilidad de apertura al conocimiento personal, y también de abrirse al Dios transcendente. El hombre se realiza en el amor a través de un itinerario de conocimiento que requiere compromiso; el ser humano se conoce desde amar y servir. El dilema pensar o amar, se supera a través de la interiorización y del compromiso.

En síntesis, la salvación posibilita que la razón supere el dilema abriéndose a la transcendencia. El ser humano se espanta al comienzo de conocerse a sí mismo y su entorno. La finitud es ocasión para la profundización en el conocimiento y para el inicio de la conversión después de descubierto el mal y el pecado. Avanzando en este proceso percibe y descubre que la imperfección, propia y la de los otros, es ocasión de purificación. La relación propicia el conocimiento; las pruebas ocasionan la purificación. La gracia se hace presente y se supera el dilema congénito viviendo como salvado. Finalmente, sucede la resolución del dilema, que no es la anulación de un polo del conflicto, sino la conjunción frente a la disyuntiva. Ambas realidades humanas son necesarias. La pequeñez, la limitación es el lugar en que la grandeza se hace presente y ensancha y capacita al ser humano para la plenificación. La compenetración de amar y pensar acontece del siguiente modo: el pensar se vuelca en el amar. El amor abarcando el pensamiento plenifica al ser humano que se abre a la transcendencia. Asombrado de las posibilidades de ser plenamente humano; admirado de una elevada mirada, y, con humildad, se pretende lo imposible: que el mal pierda poder, que lo pequeño y silencio-

(200) Cf. 4M 1, 7. Parecido afirma en Fundaciones 5, 2; Vida 12 y Camino 16-20.

(201) Ib., "aprovechar mucho en este camino y subir a las moradas que deseamos". 
so sea la fortaleza. De este modo se atisban rasgos del cumplimiento (202), de la plenificación de lo humano donde el pensar y el amar se compenetran en conocimiento amoroso.

\section{El Espíritu Santo capacita al ser humano para la autenticidad}

El dilema queda superado en la transcendencia. Se ha estudiado la asombrosa manera del proceso de salvación para la respuesta al dilema existencial humano. La superación del dilema de la razón, en Santa Teresa de Ávila, acontece en la autenticidad otorgada por el Espíritu Santo a través de la gracia.

El Espíritu Santo capacita no solo para sentir y conocer, sino también para la comunicación de la experiencia de la presencia de Dios. El Espíritu Santo habitando de forma habitual opera la transformación. Este primer texto de las cuartas moradas, ofrece la respuesta al dilema: Espíritu Santo como amor desbordante (203).

El Espíritu Santo ayuda a expresar lo inefable:

"Para comenzar a hablar de las cuartas moradas bien he menester lo que he hecho, que es encomendarme al Espíritu Santo y suplicarle de aquí adelante hable por mí para decir algo de las que quedan de manera que lo entendáis; porque comienzan a ser cosas sobrenaturales y es dificultosísimo de dar a entender, si su Majestad no lo hace, como en otra parte que se escribió hasta donde yo había entendido, catorce años ha, poco más a menos; aunque un poco más luz me parece tengo de estas mercedes que el Señor hace a algunas almas, es diferente el saberlas decir. ¡Hágalo su Majestad, si se ha de seguir algún provecho, y si no, no!" (204).

Se anuncia una nueva etapa vital que requiere una nueva manera de situarse. Teresa, partiendo de su experiencia, se propone como modelo. Se siente bastante segura de sí misma, hasta con complacencia, pero no olvida su incapacidad. La autenticidad cuando pide ayuda disuelve toda sospecha de soberbia. La autora proclama la necesidad de acogerse al Espíritu Santo para que, a partir de ahora, se diga

(202) Cf. Orbe, A., "El dilema entre la vida y la muerte", ... El autor, al final del artículo señala: "Los prenicenos, rebasando en su mayoría el consejo de Dios a la elección de la Vida, destacan la ayuda divina necesaria para su cumplimiento y su eficacia en el acto (y régimen) humano de obediencia (de fe). Ya desde Filón se anuncian las premisas de la libertad características de los hijos de Dios, superior a la mera indiferencia, contradicción y contrariedad" (534).

(203) Cf. Gutiérrez, G., Teología de la liberación, 8. ed., Salamanca, Ediciones Sígueme 1977, 245 250. La presencia de Dios en medio del pueblo es una de las promesas bíblicas. "Esta presencia, muchas veces, con el matiz de la habitación, es decir, de la presencia en un lugar determinado (Shekinah), marca el tipo de relación que se establece entre Dios y el hombre" (245). En la nueva alianza Dios se hace presente en el corazón de cada hombre (Jr 31,33), el pleno cumplimiento se da en la encarnación del Hijo de Dios, Cristo es el templo de Dios, y Pablo defenderá que cada cristiano es templo del Espíritu Santo (1Cor 6, 19; 3, 16-17). Sigue diciendo el autor: "El Espíritu enviado por el Padre y el Hijo para llevar la obra de salvación a su pleno cumplimiento, habita en cada hombre, en hombres que forman parte de un tejido bien preciso de relaciones humanas, en hombres que se hallan en situaciones históricas determinadas" (249).

(204) Cf. 4M 1, 1. 
lo que acontece entre Dios y el hombre (205), para la comprensión adecuada de lo que sucede en el ser humano a partir de esta etapa existencial. El abandono en el Espíritu Santo, convirtiéndose en su voz, transmitiendo su palabra, y siendo su copista, para que los destinatarios entiendan.

De modo reiterativo, insiste quejándose de su incapacidad, como escritora, para expresar la gracia de Dios. Y esto, a pesar de su mayor práctica, ya ha escrito casi toda su obra, especialmente, Vida y Camino, y de su mayor experiencia de la cercanía a Dios (206).

Sin embargo, su humildad manifiesta la absoluta confianza en Dios; quien dará las palabras apropiadas y le inspirará y capacitará para "dar a entender" el misterio de Dios (207). Esta certeza confiada nace de saberse instrumento y que su persona y su obra pueden ser provechosas para el futuro. El Espíritu Santo es el encargado de actualizar las "palabras, acciones y pasión de Jesús, en todos los tiempos. No se trata de un mero traer-a-la-memoria lo que sucedió históricamente de una vez por todas y pertenece al pasado, sino de representarlo, de hacerlo presente realmente. I .../ El espíritu no "espiritualiza" lo terreno, sino que muestra la ilimitada autorrevelación de Dios que late en lo encarnatorio. /.../ sin el Espíritu, que todo lo sondea, hasta las profundidades de Dios, no se puede acceder en absoluto a esas profundidades. El Espíritu es el verdadero experto que desvela esos misterios ya acontecidos en la encarnación sensible, pero ocultos a la mirada meramente humana" (208).

Teresa pide el Espíritu Santo porque la materia tratada, a partir de ahora, es sobrenatural, es lo gratuito de Dios, lo místico; es, en definitiva, la gracia. Evoca la actitud de arrodillarse para hacer teología y pide al Espíritu Santo que hable a través de ella, siempre y cuando sea para provecho de otros, para que se entienda la acción de Dios; los dones que el Señor le hace no son para provecho propio, sino para entregarlos, en actitud de renunciación. Se requiere un amor que reconozca que la abundancia y la fecundidad vienen de Dios, que las flores y los frutos no son propios y hay que ponerlos de antemano en sus manos. "Ningún árbol se aprovecha de sus propios frutos, sino que se preocupa de que sus semillas caigan en el suelo apropiado y de que nazca un nuevo árbol de frutos... los frutos serán para los pájaros, los gusanos, el propietario y hasta para el hambriento" (209). Teresa encarna el anonadamiento, pues reconoce sus límites para hablar de lo inefable; y se abandona confiadamente en el Espíritu que pone palabras a su experiencia.

El dilema ante el misterio de callar o atreverse a balbucir pidiendo ayuda, Teresa lo soluciona desvelando que es el Espíritu Santo quien clama en nosotros ¡Abba! (Ga 4, 6: "La prueba de que sois hijos es que Dios ha enviado a nuestros corazones el Espíritu de su Hijo que clama: ¡Abbá, Padre!”).

(205) Es la misma experiencia que Jesús expresa en Lc 1, 21: "En aquel momento, se llenó de gozo Jesús en el Espíritu Santo, y dijo: Yo te bendigo, Padre, Señor del cielo y de la tierra, porque has ocultado estas cosas a sabios e inteligentes, y se las has revelado a pequeños. Sí, Padre, pues tal ha sido tu beneplácito".

(206) Ib., "aunque un poco más luz me parece tengo de estas mercedes que el Señor hace a algunas almas, es diferente el saberlas decir".

(207) Ib., “¡Hágalo su Majestad, si se ha de seguir algún provecho, y si no, no!”.

(208) Cf. Baltasar, H.U. von, Meditar cristianamente, Madrid, Ediciones Encuentro, 2002, 21-25.

(209) Cf. Baltasar, H.U. von, "Oración para recibir Espíritu”, Revista Communio VI, Madrid, 1988. 
Su misma petición es un eco del clamor de Dios en la interioridad humana: "El Espíritu mismo se une a nuestro espíritu para dar testimonio de que somos hijos de Dios" (Rm 8, 16). El Espíritu Santo, por otro lado, responde a la encomienda, a través de razonamientos e ideas apropiadas, de expresar la experiencia del amor recibido a través de las mercedes del Señor.

En síntesis conclusiva, el amor se dice por la razón gracias al Espíritu Santo. El Espíritu Santo ilumina la razón para la comprensión y la expresión del amor. Así queda resumida la conclusión de toda la investigación: El Espíritu Santo, asombrosamente en el amor, capacita a la razón para la superación del dilema; y por eso se invita a todo ser humano a no contentarse con la finitud, sino a atreverse a gustar la transcendencia.

\section{RECAPITULACIÓN}

Ciertamente no se trata de una conclusión, ni de una evaluación, porque, me parece que por el momento, es precipitado dado que se está en proceso de recopilación. Solo esto se pretende y no un análisis más crítico o evaluativo. Entonces, sabiendo que el tema no queda agotado sino abierto, se recogen de manera concentrada los dilemas en sus diversas formulaciones. Previo se presentan los textos conclusivos de cada apartado en que se ha detectado la resolución de la hipótesis.

Los textos conclusivos (4M 1, 4, 6, 5, 7) aportan cierta síntesis; el capítulo primero de las cuartas moradas aborda el paso hacia la etapa mística. La manera de vivir, abordar y resolver el fundamental dilema humano, indica el tipo de relación que se establece con Dios. Además, la diferencia en la experiencia de relación con Dios señala dos niveles existenciales, los cuales se afrontan a través del contento y el gusto. En el contento el hombre es el protagonista fundamental, y corresponde a las tres primeras moradas. En el gusto, lo importante es la felicidad experimentada cuando el Reino de Dios se va cumpliendo en uno mismo, en los otros y en la Iglesia como comunidad universal.

Así en 4M 1, 4, la razón apuesta por el gusto abarcando al contento. El gozo y la alegría por las metas logradas se experimenta porque el Reino se va realizando, escatología hoy, es el contento que se va intensificando por la acción de Dios para transformarse en gusto. El hombre se humaniza colaborando y abriéndose a la acción de Dios. Teresa es consciente de su pequeñez y de su incapacidad para expresar lo inefable, por eso la gran conciencia y el énfasis en la acción de Dios.

En 4M 1, 6 se pone de manifiesto cómo el amor atrae hacia sí a la razón y de ese modo se puede avanzar en el proceso. Se explica la diferencia entre contento y gusto. Las primeras moradas dan cuenta del contento, al pasar a las más altas moradas se experimenta el gusto. El amor genera la necesidad de dar el paso para despejar el dilema avanzando en el proceso evolutivo que culmina en el gozo del amor.

El conocimiento ensancha para el amor y el dilema se aboca a la apertura y a derramarse generosamente en $4 \mathrm{M} 1,5$. Se define el contento y el gusto desde la dilatación del corazón (Salmo 118, 32). El conocimiento crea espacio para el amor, sin disyuntiva, ya que conociendo más se puede amar más. Y con un amor grande y 
ensanchado el dilema, entre encorvarse o abrirse, queda resuelto en desbordamiento. De nuevo aparece el gran deseo de la sabiduría para expresar la experiencia.

Gracias a la compenetración de razón y amor $(4 \mathrm{M} 1,7)$, el dilema atisba cierta resolución en la plenitud del pensar en el amar; se vuelca en conocimiento amoroso. Aunque no se sabe amar, lo que realmente importa no es pensar mucho sino amar mucho.

Finalmente, en 4M 1, 1 es el Espíritu Santo, quien asombrosamente en el amor, capacita a la razón para superar el dilema. Por lo tanto el ser humano no puede contentarse con la finitud sino atreverse a gustar la transcendencia.

Los dilemas y resoluciones de cada apartado, en sus diferentes expresiones, aglutinan lo fundamental del estudio.

1. Cuando la razón afronta el dilema, desde la libertad respecto a todo lo creado, salen a la luz los siguientes dilemas.

El sometimiento al poder del mal y el ceder ante la debilidad humana, se aborda desde la acción conjunta del hombre y Dios (2M 1, 5). El empeño humano desde la debilidad, o la dejadez desde la soberbia, estimula el avance en la interiorización para la perfección, la pretensión de conformarse a la voluntad de Dios (2M 1, 8). El tercer dilema, vida en armonía o en desasosiego, surge frente a la prueba; esta es necesaria y aunque rompe una inicial estabilidad, provoca crecimiento y llegada a una primera meta para el inicio de una nueva etapa. Se propone el crecimiento en la humildad y el despojo hasta la conversión definitiva $(3 \mathrm{M} \mathrm{2,1).} \mathrm{Por} \mathrm{fin,} \mathrm{ante} \mathrm{el}$ dilema de culpa o padecimiento, se remite a Jesús, padece sin culpa, que invita a la paciencia con medios adecuados $(4 \mathrm{M} 1,14)$.

El afrontamiento del dilema desde la razón libre en relación con los semejantes, descubre tres dilemas. El primero se plantea entre la indigencia del hombre o la misericordia de Dios. El empeño por asumir la condición humana se basa en la confianza en sí; además, la gracia transforma la debilidad porque el hombre es habitado por Dios (3M 1, 3). Ante el segundo dilema, seguir el camino o volver atrás, se propone el seguimiento como configuración con Cristo desde la escucha obediencial, y esto a pesar de la fuerza que arrastra al retorno $(3 \mathrm{M} 2,12)$. El dilema entre el deseo o la realidad provoca interiormente gran desasosiego. Se desea habitar con la Esposa del Cantar de los Cantares, pero la realidad personal es de angustia y desorden. A pesar de todo, se camina hacia lo más profundo donde se halla Dios; para la asunción de la fragilidad y el gozo de la presencia del esposo $(4 \mathrm{M} 1,12)$.

Si el acercamiento al dilema es desde la razón en libertad referida a la transcendencia, se recogen dos dilemas. La certeza o la incertidumbre de la salvación, se despeja en la acción de Dios y del hombre. Se necesita el esfuerzo humano, pero sobre todo el don gratuito de Dios $(3 \mathrm{M} 1,1)$. El otro dilema: contento o gusto, se resuelve pretendiendo lo más sublime. La colaboración humano-divina se muestra tanto en la alegría producida por la realización de las cosas de Dios, como en la alegría otorgada al hombre por Dios (4M 1,4).

2. El dilema se ilumina, en la creatividad del amor, a través de las relaciones interpersonales. Así la incapacidad o la posibilidad humana para la comprensión y la 
explicación del misterio de Dios y del hombre, se ilumina comunicando la experiencia de saberse y vivirse habitado por Dios y habitando en Dios (Prólogo 4). El ser humano o Dios, no puede plantearse como una elección sino como comunión; la proximidad de Dios al hombre, lo humaniza y transforma para el amor $(1 \mathrm{M} 1,3)$. A través de la comunicación se dilucidan otros dos dilemas: callar o hablar; y creer o no creer. La comunicación de la experiencia de fe transmite el amor de Dios que habita en el ser humano; es apertura a lo otro. Se accede al amor, también, a través del conocimiento de Dios comunicado a otros (1M 1,4).

El dilema se hace fecundo por la relación con Dios que dona conocimiento para amar. El hombre consigo mismo se debate entre la autenticidad o la falsedad; con los otros: envidia o generosidad; y en referencia a Dios: perfección o imperfección. La superación de estos dilemas supone: la sinceridad y la negación de las falsas imágenes; la generosidad y la confianza; y la perfección del amor. En definitiva, el conocimiento profundo conduce al amor a sí mismo, a los otros y a Dios (1M 2,17). Ante el dilema de olvido o recuerdo, y de otro modo, silencio o aviso, se apuesta por recordar el amor y por ejercer la corrección fraterna $(1 \mathrm{M} 2,18)$.

En lo cotidiano, el amor creativo frente al retroceso o al avance, atenúa la importancia del esfuerzo discursivo, entendimiento, para el traslado hacia el gozo

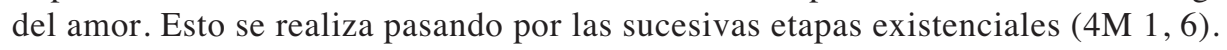

3. El dilema se transforma por la progresiva compenetración de amor y razón. Cuando tiene primacía la razón los dilemas planteados y resueltos son los siguientes. Entre el comienzo o la continuación en el camino, se opta por avanzar en el conocimiento. Entre la pretensión o la realidad, se aceptan ambas: la permanencia a la que se accede, a través de la fugaz realidad. La fe descubre sentido razonando que el amor es la dirección apropiada para la realización humana, frente al sinsentido de toda la realidad avocada a la muerte $(2 \mathrm{M} 1,4)$. Aun se expresan dos dilemas más: humildad o soberbia, y, vigilancia o descuido. La respuesta se vislumbra en la permanente vigilancia del seguimiento $(3 \mathrm{M} 1,7)$. El dilema entre razón o amor se resuelve en progresiva armonización $(3 \mathrm{M} 2,7)$.

Cuando la razón y el amor se equiparan, los dilemas se transforman por compenetración. Ante temor o confianza; olvido de la flaqueza o cuidado de sí, es necesario que la razón no caiga en el temor, y el amor se abra a la confianza (3M 2, 8). La comunicación resuelve el dilema de la eficacia o ineficacia de la acción de Dios; es decir, la comunicación es signo de la experiencia receptiva del hombre que acepta los dones de Dios (3M 2,11).

Si el amor ostenta la supremacía, el dilema entre el seguir o volver atrás, se apuesta por el progresivo conocimiento hacia el amor $(4 \mathrm{M} 2,8)$. En este proceso de conocimiento, se opta por el esfuerzo o por el inmerecimiento. El humilde reconocimiento del inmerecimiento posibilita la respuesta a la llamada amorosa al seguimiento de Cristo (4M 2,9). El contento o el gusto; la torpeza o el acierto en la expresión; y la ignorancia o la sabiduría se van inclinando hacia el segundo término. El conocimiento ensancha la capacidad humana para la aceptación del amor $(4 \mathrm{M} 1,5)$. 
4. La superación del dilema se produce de modo asombroso en la capacidad humana de transcender: la persona desde sus circunstancias se abre a la conversión en el proceso salvador. El dilema frente al mal se supera apostando por el arrinconamiento del pecado, sabiendo del poder del mal y de la debilidad humana $(1 \mathrm{M} \mathrm{2,5).}$ El gran dilema humano consiste en: encorvarse altivamente o enderezarse humildemente; desconocimiento o conocimiento; apego al mundo o modesta renuncia; estancamiento o avance en las moradas. Se supera dicho dilema poniendo la mirada más allá de sí, en la definitividad de Cristo $(1 \mathrm{M} \mathrm{2,11).}$

La prueba va capacitando para la transcendencia, para el enriquecimiento en el proceso salvador. La prueba ¿es engaño o es favor de Dios? El dolor por la propia miseria ¿es falta o es ganancia? Se responde que ambas disyuntivas son favor y ganancia, pero cuando se asume la condición de limitación $(3 \mathrm{M} 2,2)$. Una manera asombrosa que supera el dilema entre lo propio o lo ajeno, la uniformidad o pluralidad, es gracias a la comunión, la catolicidad, la universalidad $(3 \mathrm{M} 2,13)$.

La superación del dilema se realiza en la plenificación de lo humano, en la meta de la salvación, el amor. El dilema entre pequeñez o grandeza se resuelve asombrosamente de este modo: la grandeza de Dios se refleja en lo profundo de la creatura $(4 \mathrm{M} 2,5)$. El dilema se supera desde la sabiduría divina que inunda, de manera delicada, la ignorancia humana sobre el amor. El ser humano se asombra y sobrecoge ante la presencia de Dios (4M 2,6). El dilema pensar o amar, se supera en la interiorización y en el compromiso $(4 \mathrm{M} 1,7)$.

5. El dilema se supera, definitivamente, gracias al Espíritu Santo que capacita al ser humano para la autenticidad. Ante el dilema de callar frente al misterio o atreverse a balbucir pidiendo ayuda, Teresa muestra cómo es el Espíritu Santo quien ayuda en la expresión de lo inefable. El Espíritu Santo en nosotros ayuda a la sabia comunicación de la experiencia de los dones recibidos del Señor. El Espíritu Santo, impulsa a superar el dilema de la razón en el amor.

\section{RESUMEN}

Santa Teresa de Ávila es redescubierta en la segunda mitad del XX y se le adjudica un magisterio empírico de la experiencia. A partir de la separación entre mística y teología se convoca a un diálogo que supere el dilema entre finitud e infinitud. La autora sigue vigente, presente en la postmodernidad.

La obra Castillo Interior aborda el crecimiento humano, haciendo un paralelismo con la edad cronológica, desde los dieciséis años, momento de plantearse las opciones fundamentales de la existencia, hasta los cuarenta años, aproximadamente, edad en la que se produce un quiebre fundamental.

La hipótesis que se presenta en esta investigación es: la razón humana puede resolver su dilema congénito. En la obra estudiada se formula de esta manera: contentarse con la finitud o atreverse a gustar la transcendencia. Y se apuesta porque El Espíritu Santo capacita a la razón para superar el dilema y plenificarse asombrosamente en el amor. Se ofrecen valiosos aportes que dan acceso a lo profundo de la vida humana recorriendo las distintas moradas, a través de las cuales se afrontan los diversos dilemas existenciales. 


\section{ABSTRACT}

Saint Theresa of Avila was rediscovered in the second half of the $20^{\text {th }}$ century and attributed an empirical magisterium of experience. From the starting point of the separation between the mystical and the theological, a dialogue is invoked that overcomes the dilemma between finitude and infinitude. The author is still valid today, and present in post-modernity.

Her work Interior Castle treats of human growth, establishing a parallelism with chronological age, from sixteen years old-the moment to face fundamental options regarding existence-up to approximately forty years of age, the stage at which a fundamental break is produced.

The hypothesis that this investigation presents is: Human reason can resolve its congenital dilemma. In the work studied, it is formulated in this manner: to be content with finitude or dare to taste transcendence, and stakes itself on the Holy Spirit capacitating reason so as to overcome the dilemma and fulfill itself astonishingly in love. Valuable insights are offered in the work that permit access to the depths of human life, traveling through different dwellings, through which diverse existential dilemmas are confronted. 
